Good Intents, but Low Impacts:

Diverging Importance of Motivational and Socio-Economic Determinants

Explaining Pro-Environmental Behavior, Energy Use, and Carbon Footprint

Stephanie Moser

Centre for Development and Environment (CDE), University of Bern.

Silke Kleinhückelkotten,

ECOLOG-Institut für sozial-ökologische Forschung und Bildung, Hannover. 


\begin{abstract}
Earlier research has yielded contradictory results as to the main drivers of environmentally significant behavior. Intent-oriented research has stressed the importance of motivational aspects, while impact-oriented research has drawn attention to people's socio-economic status. In this study, we investigated the diverging role of a pro-environmental stance under these two research perspectives. Data from a German survey $(N=1,012)$ enabled assessment of per capita energy use, and individual carbon footprints (impact-related measures), proenvironmental behavior (an intent-related measure), and behavior indicators varying in environmental impact and intent. Regression analyses revealed people's environmental selfidentity to be the main predictor of pro-environmental behavior; however, environmental self-identity played an ambiguous role in predicting actual environmental impacts. Instead, environmental impacts were best predicted by people's income level. Our results show that individuals with high pro-environmental self-identity intend to behave in an ecologically responsible way, but they typically emphasize actions that have relatively small ecological benefits.
\end{abstract}


Good Intents, but Low Impacts: Diverging Importance of Motivational and SocioEconomic Determinants Explaining Pro-Environmental Behavior, Energy Use, and

\section{Carbon Footprint}

Industrialized and emerging countries continue to emit high levels of greenhouse gases based on their consumption of fossil energy sources, which is alarming in light of associated climate change risks (Intergovernmental Panel on Climate Change [IPCC], 2014). Household-driven greenhouse gas emissions represent a major share of overall total emissions (e.g., European Environment Agengy [EEA], 2013; United Nations Environment Program [UNEP], 2010). Thus, changing individual and household-level consumption is crucial for conservation of natural resources in general and for combatting fossil energyrelated climate risks in particular (UN General Assembly, 2015).

The specific household-level energy-consumption domains that appear to have an especially high emissions-related environmental impact are housing, transportation, and nutrition (EEA, 2013; Tukker \& Jansen, 2006). However, the emission contributions of these domains vary strongly between households depending on, for example, household size, income, or geographic location (e.g., Jones \& Kammen, 2011). Policies and interventions to reduce individual and household-level carbon footprints are more effective if they are tailored to different energy-relevant behaviors and to different population segments. To enable such tailored policies and interventions, we require sound knowledge of what determines and motivates people's consumptive decisions and practices.

Identifying motivational factors influencing environmentally significant behavior and fostering pro-environmental behavior are key objectives of environmental psychological research (e.g., Kastner \& Matthies, 2014). In investigating pro-environmental behavior, environmental psychologists have primarily been interested in their subjects' underlying motivational and intentional behavior structure, that is, what individuals intend to do to 
protect the environment as seen through their own eyes (e.g., Kastner \& Matthies, 2014; Stern, 2000; 2011).

In recent years, however, this sort of intent-oriented research perspective has been criticized for ignoring the actual environmental impact of people's behavior, whatever their intent (Csutora, 2012; Kastner \& Matthies, 2014; Stern 2000, 2011). Some researchers have argued that environmentally significant behavior should be understood and measured according its environmental impact, namely "the extent to which it changes the availability of materials or energy from the environment or alters the structure and dynamics of ecosystems or the biosphere itself”' (Stern, 2000, p. 408). In the resulting impact-oriented research perspective, environmentally significant behaviors are distinguished and rated according to different measurable material criteria. These might include, for example, the amount of energy needed (directly or indirectly) to produce, transport, use, and dispose of equipment deployed in connection with a particular behavior, or the carbon dioxide equivalents emitted as a result of the same. In complement to the intent-oriented perspective, this impact-oriented perspective reveals that intention-driven pro-environmental behavior can sometimes fail to have significant beneficial environmental impacts (Stern, 2000). Further, and just as important, it also reveals that environmentally significant behavior does not always follow directly from people's expressed or personally held intent. Although intent-oriented and impact-oriented behavior frameworks may overlap in some cases, the two perspectives have been used separately by researchers to operationalize environmentally significant behavior in distinct ways. As we shall see, researchers from the two strands tend to disagree about the importance of underlying behavioral determinants. While intent-oriented behavior research emphasizes people's motivations to protect the environment, it is well known from impactoriented behavior research that factors such as income, household size, or geographic location strongly determine people's lifestyles and resulting environmental impacts. 


\section{Intents vs. Impacts: Two Complementary Research Perspectives on Environmentally}

\section{Significant Behavior}

\section{Intent-Oriented Perspective}

Intent-oriented research has only recently broadened its focus from researching specific pro-environmental actions to researching more comprehensive, overall proenvironmental behavior patterns and environmentally friendly lifestyles. Researchers have sought to reveal cross-behavioral, cross-situational predictors that reflect a more abstract, overall pro-environmental motivation or environmental stance (Thøgersen \& Ölander, 2006; Whitmarsh \& O'Neill, 2010). In so doing, social environmental researchers adapted the concept of identity from cognitive sociological and social psychological research by claiming that people differ in the degree to which they hold a "green" or environmental self-identity.

Self-identity signifies who a person is and may become, and who he/she is not and wants to avoid becoming. An identity-based motivation corresponds with readiness to engage in different, identity-congruent actions, such as the purchase of congruent products or lifestyle choices (Oyermann, 2009). People hold multidimensional social and personal identities (Brekhus, 2008). The behavioral relevance of a particular identity depends on the decision context (whether a given identity is activated by situational cues) as well as the degree to which a particular action contributes to the sense of identity (Oysermann, 2009). Identities emerge and shift over longer time periods through biographical and identity changes (Brekhus, 2008).

Translated into the context of pro-environmental behavior, self-identity has been understood as the extent to which an individual views him- or herself as the type of person who behaves in an environmentally friendly manner, i.e., whether one self-identifies using labels such as “eco-conscious” (Cook, Kerr, \& Moore, 2002; Steg, Bolderdijk, Keizer, \& Perlaviciute, 2014; van der Werff, Steg, \& Keizer, 2013a). Environmental self-identity has been empirically tested in previous studies under the intent-oriented perspective. It has been 
shown to predict various pro-environmental behaviors in a cross-situational way (Gatersleben et al., 2014; van der Werff, Steg, \& Keizer, 2013b; Whitmarsh \& O'Neill, 2010) and to mediate the relationship between values or environmental concerns, on the one hand, and a variety of general pro-environmental behaviors (Gatersleben et al., 2014; Whitmarsh \& O'Neill, 2010) or energy-saving behaviors, on the other (van der Werff et al., 2013a, 2013b). Moreover, environmental self-identity has been shown to explain variance in proenvironmental behavior better than behavior-specific factors (Cook et al., 2002; Fielding, McDonald, \& Louis, 2008; Gatersleben et al., 2014; Nigbur, Lyons, \& Uzzell, 2010; Sparks \& Shepherd, 1992; Whitmarsh \& O'Neill, 2010). Finally, environmental self-identity has proven to be a better predictor of intent-oriented pro-environmental behavior than socioeconomic factors (Whitmarsh \& O'Neill, 2010).

In sum, having a pronounced environmental self-identity (“being green”) may translate into commitment to environmental goals and increased readiness to act in an identity-congruent way - for example, by consuming fewer natural resources or switching to consumption of more environmentally friendly products (Clayton \& Myers, 2015) - as long as situational cues activate the "green" identity and it is not negated by competing identities (e.g., that of being wealthy).

\section{Impact-Oriented Perspective}

Research from an impact-oriented perspective has produced insights about behavioral determinants that diverge from those of the intent-oriented perspective. Studies of impactoriented behavior measures - e.g., people's ecological footprint, overall energy consumption, or greenhouse gas emissions - have cast doubt on the predictive power of pro-environmental motivational variables. These studies consistently point to people's income level as the most significant determinant of their environmental impact. In this way, consumers with higher incomes tend to have bigger ecological footprints, use more energy per year, and emit more greenhouse gases than consumers with lower incomes. In addition, geographical 
considerations (e.g., climatic zone of residence, urban versus rural locations) and individual socioeconomic characteristics (e.g., age, education level, gender, homeownership status) have been shown to influence people's environmental impact (Abrahamse \& Steg, 2009; Bruderer Enzler \& Diekmann, 2015; Csutora, 2012; Gatersleben et al., 2002; Holden, 2004; Kennedy, Krahn, \& Krogman, 2014; Kennedy et al., 2015; Keuschnigg \& Schubert, 2013; Notter, Meyer, \& Althaus, 2013). Finally, household size has proved to be an important predictor of environmental impact. Household-related environmental burdens tend to increase with the number of household members, but not proportionally - i.e. the per capita rates of environmental burdens are generally lower in households with several members than in single-person households. Thus, studies measuring household-level environmental impacts generally find a positive relationship between the number of household members and household energy use or greenhouse gas emissions (e.g., Abrahamse \& Steg, 2009; Gatersleben et al., 2002; Kennedy, Krahn, \& Krogman, 2014), whereas studies assessing per capita environmental impacts on the individual level show a negative relationship (e.g., Bruderer Enzler \& Diekmann, 2015; Holden, 2004; Keuschnigg \& Schubert, 2013).

Regarding the relevance of psychological variables in explaining environmental impact, the evidence is mixed. Several studies did not find any significant effect of psychological variables on people's overall energy use or their different energy-relevant behaviors after controlling for socioeconomic factors (Abrahamse \& Steg 2009; Bilharz \& Schmitt 2011; Csutora, 2012; Holden, 2004; Tabi, 2013; Poortinga, Steg, \& Vlek, 2004). However, several other studies have identified psychological variables - such as environmental concerns, environmental awareness, or moral obligation - that appear to influence people's environmental impact, albeit with less explanatory power than socioeconomic variables (Bruderer Enzler \& Diekmann, 2015; Gatersleben et al., 2002; Hunecke, Hauenstein, Böhler, \& Grischkat, 2010; Hunecke, Haustein, Grischkat, \& Böhler, 
2007; Kennedy et al., 2014, 2015; Keuschnigg \& Schubert, 2013; Thøgersen \& Grønhøj, 2010; Whitmarsh, 2009).

A very limited number of studies have chosen to adopt a complementary, combined approach bringing together intent-oriented and impact-oriented perspectives on environmentally significant behavior, thus enabling direct comparison (Bruderer Enzler \& Diekmann, 2015; Gatersleben et al., 2002; Kennedy et al., 2015; Whitmarsh, 2009). Using different psychological variables (e.g., environmental values, environmental awareness, environmental concerns, or moral obligations), these studies show coinciding evidence for a high explanatory power of psychological variables for intent-oriented pro-environmental behaviors, but a much weaker, although significant, effect of psychological variables on impact-oriented measures. In these studies, environmental impacts were best explained by people's income and other socioeconomic characteristics (except the study of Whitmarsh, 2009, which excluded income).

In sum, the results of prior studies suggest that people's pro-environmental motivational stance is strongly related to specific, intention-driven pro-environmental behaviors, but is only loosely related to their overall environmental impact. Instead, people's overall environmental impacts are best explained by socioeconomic factors, especially income level. In light of such findings, Stern (2011) has highlighted the importance of better understanding the contribution of psychological variables to explain overall environmental impact. He and others have called for more psychological research examining asymmetries in the determinants of intent-oriented versus impact-oriented behavior, with particular emphasis on high-impact behaviors (Kennedy et al., 2014; Stern, 2011; Whitmarsh, 2009).

\section{The Present Study}

In the present study, we sought to explore the diverging insights that emerge from the intent-oriented and impact-oriented research perspectives vis-à-vis environmentally 
significant behavior, in particular energy use and related greenhouse gas emissions. For this purpose, we compared and contrasted socioeconomic and psychological determinants of different energy-related behaviors, which vary in terms of their explicitness of underlying pro-environmental intent (expressed by study participants) as well as in terms of their actual environmental impact. The data used in our study were derived from a larger survey conducted on behalf of the German Environment Agency (UBA), for a detailed documentation see Kleinhückelkotten, Neitzke, and Moser (2016).

First, in line with the procedure of previous studies (Bruderer Enzler \& Diekmann, 2015; Gatersleben et al., 2002; Kennedy et al., 2015), we compared an intent-oriented and an impact-oriented perspective on environmentally significant behavior at an aggregated behavior level, investigating the predictive power of age, gender, education level, income, number of household members, homeownership, and residential area on yearly per capita energy use and carbon footprint, in addition to participants' self-reported pro-environmental behavior. These socioeconomic characteristics have been shown to predict impact-oriented behavior in earlier studies (e.g., Abrahamse \& Steg, 2009; Bruderer Enzler \& Diekmann, 2015; Csutora, 2012; Gatersleben et al., 2002; Kennedy et al., 2014, 2015; Keuschnigg \& Schubert, 2013; Notter et al., 2013).

Second, we designed our study to investigate the effects of our set of determinants on a variety of concrete, domain-specific, personal behaviors differing in terms of their environmental impact as well as assumed underlying intention. The overall environmental impact of each person is comprised of numerous individual behaviors or actions, which are in turn shaped by diverse structural, socioeconomic, and psychological variables (Gatersleben et al., 2002; Stern, 2000). One consequence of this is that self-described environmentally concerned people may try to act in an environmentally sound way, but they end up emphasizing smaller actions that do not appreciably diminish the overall environmental impact of their lifestyle. We provided detailed results regarding participants' per capita living 
space, energy used for household appliances, meat consumption, car use, and vacation travel, all of which are indicators of behaviors and actions that make particularly high contributions to overall environmental impact (Girod \& de Haan, 2010; Jungbluth, Itten, \& Stucki, 2012; Notter et al., 2013; Tukker \& Jansen, 2006). We contrasted these high-impact behaviors with indicators with lower-impact and more intent-oriented focus, such as possession of energyefficient household appliances or purchase of environmentally friendly products. These behaviors have been linked to pro-environmental motivation in previous studies (Gatersleben et al., 2014; Gatersleben et al., 2002; van der Werff et al., 2013a, 2013b; Whitmarsh, 2009; Whitmarsh \& O'Neill, 2010).

Third, we more closely explored the relationship between income, environmental selfidentity, and behavior. We assumed that if self-identity does not show a direct effect of lower environmental impacts, it might play a moderating role on the relationship between income and high-impact behavior. In other words, we supposed that income predicts high-impact behavior more strongly for those people with low environmental self-identity, whereas high self-identity may counterbalance the income effect and thus the relationship between income and behavior may appear nonexistent or smaller for people with high environmental selfidentity.

\section{Method}

\section{Survey Procedure and Recruitment}

Data were gathered in face-to-face interviews throughout Germany in March and April 2014 by a market research institute using computer assisted personal interviews (CAPI, e.g., Giesen, Meertens, Vis-Visschers, \& Beukenhorst, 2012). German-speaking residents aged 18 years and older were recruited from the market research institute's existing participant pool with the help of quota sampling criteria including age, gender, number of households, and household size. Interviews lasted an average of 45 minutes. 


\section{Participants}

A total of 1,012 interviews were completed. The mean age of participants was 49.8 years $(S D=7.6), 50.9 \%$ were females. The distribution of highest completed education level was as follows: $39.5 \%$ of participants had completed secondary school, $32.7 \%$ had completed intermediate school, 20.7\% had a higher education qualification, and 5.6\% had completed an advanced degree (1.5\% missing data). Net monthly per capita household income ranged from $€ 187.50$ to $€ 5,250(M=€ 1,186.70 ; S D=€ 624.3)$; or, in US dollars, a range of $\$ 258.75$ to

$\$ 7,245\left(M=\$ 1,637.66, S D=\$ 861.53^{1}\right)$. For further sample characteristics see Table 1 . When compared with official German population statistics (Federal Statistical Office, 2014, 2015a), the incomes of participants in our sample were revealed to be slightly below average among the more highly educated, higher net earners (i.e., monthly incomes over $€ 5,000$, or $\$ 6,900$ ), and slightly above average among low- and medium-level education, mid-range earners (i.e., monthly incomes of $€ 2,500-€ 3,500$, or $\$ 3,450-\$ 4,830$ ). We refrained from weighting our sample data for representativeness, however, as the goal of our study was more to investigate relationships between variables than to draw conclusions about absolute levels of distribution.

\section{Measures}

Face-to-face interviews with respondents were conducted with the help of a standardized questionnaire. Notably, interviews with individual respondents from a household typically generate data that is only of limited validity regarding overall household consumption (Seebauer, Fleiss, \& Schweigart, 2016). Thus, in the present study, we emphasized assessment of natural-resource consumption at the level of the individual, wherever feasible, rather than the household. When possible, questionnaire items were framed to assess individual behaviors. Nevertheless, for the sake of simplicity, certain consumption-related items - e.g., apartment size, energy-consuming appliances in household - were assessed at 
the household level. In these cases, a per capita rate was calculated for further analysis by dividing the respondent's indication by the number of household members.

\section{Pro-environmental behavior}

General pro-environmental behavior was operationalized according to participants' selfreported estimations of their own efforts to save natural resources. This was done based on the following two survey items: "I organize my daily life so as to use as few natural resources as possible"; and, "I even try to use as few natural resources as possible when it requires substantial extra costs and effort'. Responses were measured on a 5-point scale, ranging from $1=$ "I totally agree" to $5=$ "I totally disagree". The items displayed adequate reliability (Cronbach's $\alpha$ of .76). For subsequent analysis, the mean of the two items was used $(M=2.94 ; S D=.90, \mathrm{cf}$. Table 2$)$. In assessing explicit self-estimations of resource use, we referred to the procedure used by Whitmarsh (2009) and refrained, due to interview duration limitations, from asking about the frequency of different environmentally significant behaviors as has been commonly done to operationalize pro-environmental behavior in other studies (e.g., Bruderer Enzler \& Diekmann, 2015; Gatersleben et al., 2002; Kennedy et al., 2015).

\section{Per capita energy use and carbon footprint}

For the present study, we used assessments of annual per capita energy consumption and greenhouse gas emissions (also referred to as "carbon footprint") as proxies for impactoriented environmentally significant behavior. We assessed the two variables according to commonly used procedures for calculation of ecological footprints. To enable exploration of inter-individual differences, we implemented a so-called bottom-up assessment method based on process analyses. This entails calculating per capita impacts using data from individual respondents and weighting them with insights derived from independent impact assessment studies, rather than simply estimating per capita impact based on population-level averages 
(the so-called top-down method; Galli et al., 2012; Weidema, Thrane, Christensen, Schmidt, \& Løkke, 2008; Wiedmann \& Minx, 2008). While a variety of footprint calculators exist that have proven successful as tools for public communication and awareness building, several of them display inconsistencies and insufficient transparency regarding underlying methods and estimates (Čuček, Klemeš, \& Kravanja, 2012; Weidema et al., 2008). We therefore adapted and supplemented existing calculation methods in an effort to obtain more reliable footprint results; a detailed description of our procedure is documented in Kleinhückelkotten and Neitzke (2016). Our assessments drew on a combination of survey responses and interviewer observations. In addition, we attempted to obtain information from respondents' actual energy bills; unfortunately, less than half of the respondents were able to provide their energy bills, so we ultimately refrained from using these data in further analysis. We weighted the data based on indications from existing impact assessment studies focused on Germany (e.g., International Institute for Sustainability Analysis and Strategy [IINAS], 2012; Kutzner, Hertle, \& Lambrecht, 2014; Max Rubner Institute [MRI], 2008; Peters, 2010; German Environment Agengy [UBA], 2014; 2012). Per capita energy use (in Kilowatt hours per year, or $\mathrm{kWh} / \mathrm{a}$ ) and carbon footprint (in kilograms $\mathrm{CO}_{2}$ emitted per year, or $\mathrm{kgCO}_{2} \mathrm{e} / \mathrm{a}$ ) were calculated for the subdomains of housing, transportation, and food. While our assessments of energy use for housing and transportation focused solely on direct use, our assessments of energy use for food included estimates of indirect energy use (e.g., energy used to produce and transport food). Overall environmental impacts were calculated by combining these various measures, properly weighted according to their energy impacts. In online Appendix A, we illustrate how overall energy use was derived from different sources, and how specific survey questions contributed to the assessment.

The average per capita energy use in our sample was 13,677 kWh per year. Apart from the high variance $(S D=7,130)$, what is particularly noticeable is the positive skewness (see Table 2). This means that the energy level consumed by the decile of respondents with 
the highest consumption level equals the one of the $40 \%$ with the lowest consumption level. Because of differences in accounting methods, it is not possible to directly compare our per capita energy use estimates with those of official national statistical agencies. For example, official national statistics allocate mobility-related energy use (e.g., personal vehicle use) to a separate transportation category, not to households themselves as was done in our study. Nevertheless, in terms of the housing domain, if we weight our per capita average for household size, our calculations appear to be very consistent with official national energy accounting statistics in this domain (Federal Statistical Office, 2015b; n.d.).

The average per capita carbon footprint in our sample was $4,547 \mathrm{kgCO}_{2} \mathrm{e}$ per year $(S D=2,189$; again displaying positive skewness). Similar to energy use, direct comparisons to official national emissions statistics are difficult. Our partial sums in different domains (e.g., home heating) are comparable to those found in a study of a suburban area near Dortmund (Kutzner et al., 2014), but are slightly higher than those found in a study of an urban area in Munich (Keuschnigg \& Schubert, 2013). In our subsequent analysis, we used log-transformed measures of per capita energy use and carbon footprints because of their initial positive skewness.

\section{Behavior indicators of energy use}

Table 2 provides an overview of the descriptive statistics used for different behavior indicators of energy use as well as the underlying intent-oriented or impact-oriented perspective.

Living space. We asked participants to estimate the size of their main residence (excluding the basement and attic) in square meters $\left(\mathrm{m}^{2}\right)$. Only 10 respondents claimed not to know the size of their residence. Next, we divided the indicated measure by the number of household members. Average per capita living space in our sample was $40.19 \mathrm{~m}^{2}\left(S D=19.99 \mathrm{~m}^{2}\right)$, with a maximal value of $305 \mathrm{~m}^{2}$. Residence size positively correlated with other housing indicators in our study, such as number of rooms $(r=.75, p<.001)$ and number of floors 
$(r=.59, p<.001)$. The mean sizes per household type we found were similar to those reported by the German Federal Statistical Office (2011). Due to its positive skewness, a logtransformed measure of per capita living space was used for subsequent analysis.

Energy-efficient appliances. We surveyed participants about the presence and energyefficiency class of the following appliances in their home: refrigerator, refrigerator/freezer (combined), freezer, washing machine, dryer, and dishwasher. Reported numbers of appliances in the highest energy-efficiency classes $\left(\mathrm{A}^{+}\right.$to $\left.\mathrm{A}^{+++}\right)$were then added together and divided by the number of household members to enable per capita estimates. On average, participants owned .72 appliances in the highest energy-efficiency classes, with a maximum number of 5.

Energy consumption of appliances. Energy use for appliances was calculated by weighting the number of appliances owned with the indicated frequency of use and corresponding assumptions about energy needed based on energy class. The sum of energy used for household appliances was then divided by the number of household members to obtain per capita estimates (for details, see online Appendix A). Mean per capita consumption of household appliances was $525.60 \mathrm{kWh} / \mathrm{a}$, with a maximum of $2954.40 \mathrm{kWh} / \mathrm{a}$.

Meat consumption. Participants were informed that men and women in Germany eat an average of $160 \mathrm{~g}$ and $80 \mathrm{~g}$ of meat per day, respectively (based on MRI, 2008), and then were asked "How much meat or meat products do you eat per day?" Answer categories ranged from 1 = "I eat much more meat than the average consumer" to $6=$ "I do not eat meat at all" $(M=3.10, S D=.93)$.

Organic foods. Participants were asked how much importance they attach to buying organically produced goods when purchasing the following goods (four items): vegetables and salads; fruits; milk / milk products (e.g., cheese); and meat / meat products. Mean of the four items was used for subsequent analysis: $M=2.98, S D=.79$, Cronbach's $\alpha=.94$. 
Car trips. Car use was assessed by asking "How many kilometers have you travelled in passenger vehicles over the last year (as driver or passenger)?” Answer categories ranged from $1=$ "less than $1,000 \mathrm{~km}$ per year" to $8=$ "more than 30,000 per year". Participants who stated never using passenger vehicles were coded as 0 . The median was $3=" 5,000$ to $10,000 \mathrm{~km}$ per year". This proxy indicator for car use was shown to be positively correlated to a more sophisticated measure for energy use in daily transportation $(r=.55, p<.001)$, comprising questions about weekly trips for commuting, shopping, and leisure time, weighted by distance and travel mode, which was part of the assessment of the overall energy use and carbon footprint calculations (cp. online Appendix A).

Vacation trips. Holiday-related energy use was assessed with one question about the longest distance travelled for vacation purposes in the last year. Answer categories ranged from $1=$ "1 to $50 \mathrm{~km}$ " to $8=$ "more than $5,000 \mathrm{~km}$ "; those who did not take vacation in the last year were coded as missing. The median was $5=$ "500 to $1,000 \mathrm{~km} "$

\section{Behavior determinants}

Environmental self-identity was assessed using two survey items, adapted from previous studies (Gatersleben et al., 2014; Hinds \& Sparks, 2008; Sparks \& Shepherd, 1992; van der Werff et al., 2013a, 2013b; Whitmarsh \& O'Neill, 2010), which read as follows: "I think of myself as a consumer who cares about saving natural resources"; and, "A resource-saving lifestyle is an important part of who I am". Responses were measured on a 5-point scale, ranging from $1=$ "I totally agree" to 5 = "I totally disagree". The two items proved to be reliable measures (Cronbach's $\alpha=.74$ ). For subsequent analysis, the mean score was used $(M=2.94 ; S D=.94)$.

Socioeconomic behavior determinants included age, gender, education level, income, household size (i.e., the number of people living in the same household), homeownership status, and residential area. Age, household size, gender, highest education level, and homeownership were assessed with corresponding survey items. Further, participants were 
asked to report their net monthly household income, which we divided by the number of household members to obtain an estimate of net monthly income per capita. Residential location was categorized in a binary way as follows: "urban" for locations of $>20,000$ inhabitants; and "rural" for locations of $<20,000$ inhabitants.

\section{Results}

\section{Predicting Pro-environmental Behavior vs. Environmental Impacts}

We conducted regression analyses predicting (self-reported) pro-environmental behavior and environmental impacts (energy use and carbon footprint) with our set of psychological and socioeconomic determinants. The results of these analyses are shown in Table 3 (for correlations between the predictors and the different dependent variables, see online Appendix B). As expected, environmental self-identity was the strongest and only significant predictor of pro-environmental behavior $\left(\beta=.70, p<.001, R^{2}=.52\right)$; none of the socioeconomic variables reached significance in this analysis. By contrast and other than expected, environmental self-identity did not predict overall energy use or carbon footprint; the corresponding regression weights were negligible with $\beta=-.09, p=.003$, and $\beta=-.08$, $p=.008$. Further, and in contrast to previous studies, the unexpected direction of our regression weights revealed that higher levels of environmental self-identity were associated with slightly higher levels of energy use and bigger carbon footprints (note that the answer scale of environmental self-identity was coded such that low values mean high estimates of environmental self-identity).

In line with previous studies, our regression analyses revealed a dominant role of socioeconomic factors in explaining participants' overall environmental impact. The most important predictor proved to be income $(\beta=.25, p<.001$ for energy use, and $\beta=.27$, $p<.001$ for carbon footprint), followed by homeownership $(\beta=.22, p<.001$, and $\beta=.19$, $p<.001$ respectively). In other words, participants with higher incomes and those owning 
homes tended to consume more energy and displayed bigger carbon footprints than participants with lower incomes and those who rent. Significant, albeit weaker, regression weights were found for age, gender, and household size: elderly people, women, and those living with a greater number of people tended to use less energy and emit less greenhouse gases (per capita). Negligible effects were found with respect to education level and residential area. With $R^{2}=.19$ for energy use and $R^{2}=.20$ for carbon footprint, the explained variances of our models were satisfactorily high.

\section{Predicting Different Behavior Indicators of Energy Use}

Of course, overall energy use and carbon footprint are both highly aggregated behavior impact measures. We therefore investigated in a second step the predictor patterns of different behavioral indicators with varying degrees of their contribution to environmental impact, as well as intent-oriented significance. We tested the same set of predictors as before. In the following, we first describe our results for indicators in the housing domain, followed by results for indicators in the domains of food and transportation.

In a slightly less distinct way, indicators in the housing domain confirmed the above reported patterns in the predictor sets among pro-environmental behavior and the environmental-impact measures. As shown in Table 4, high levels of environmental selfidentity were, as expected, significantly related with possession of more energy-efficient appliances $(\beta=-.15, p<.001)-$ our intent-oriented behavior indicator. However, unexpectedly, high levels of environmental self-identity were also related with slightly bigger living spaces $(\beta=-.04, p=.043)$, and higher energy consumption of household appliances $(\beta=-.13, p<.001)-$ our impact-oriented indicators. In both examples, however, socioeconomic factors were more important in explaining variance than environmental selfidentity. Bigger living spaces were related with smaller numbers of household members, homeownership, higher incomes, and increasing age $\left(R^{2}=.65\right)$. Higher energy consumption 
of household appliances was related with smaller numbers of household members, income, age, and education level $\left(R^{2}=.22\right)$.

On the other side, participants were more likely to report possessing more energyefficient appliances if they lived in households with fewer household members, had higher incomes, were younger, were homeowners, or were female $\left(R^{2}=.19\right)$.

In the food domain, environmental self-identity significantly explained variance in meat eating - our (high) impact-oriented indicator in this domain. As shown in Table 5, participants reporting higher environmental self-identity also reported eating less meat in comparison with average consumers $(\beta=-.09, p=.004)$. However, even more predictive power was associated with gender $(\beta=.32, p<.001)$ - with women more frequently reported eating less meat than the population average - followed by household size $(\beta=-.09, p=$ .032 ), indicating that meat consumption is greater in bigger households. Our intent-oriented indicator - i.e., purchase of organic food - was best predicted by environmental self-identity $(\beta=.39, p<.001)$. Interestingly, socioeconomic factors - especially homeownership, gender, and education level - also accounted for some of the variance of purchase behavior.

Finally, the two high-impact indicators in the transportation domain again reinforced the patterns described above. As shown in Table 5, environmental self-identity was not significantly related with distances traveled on vacation $(\beta=.03, p=.507)$; further, environmental self-identity was (unexpectedly) negatively related with distances traveled in passenger cars $(\beta=-.11, p<.001)$. In this way, participants claiming high environmental self-identity showed no tendency to refrain from long-distance vacations, and even recorded more kilometers in passenger cars than participants with low environmental self-identity. Again, however, socioeconomic factors displayed the greatest explanatory power: distances traveled on vacation mainly depended on participants' income, household size, and residential area. With respect to distances traveled in passenger cars, all our socioeconomic 
predictors (with the exception of education level) showed significant predictive power, especially number of household members and income level.

\section{Relationships between Self-identity, Income, and Behaviors}

Last of all, we were interested in exploring in greater detail the relationships between environmental self-identity, income, and the different behavior variables. Environmental selfidentity was correlated with income $(r=-.14, p<.001$, cp. online Appendix B), indicating that people with higher incomes hold more positive levels of environmental self-identity. Our regression analyses reinforced the assumption that the effect of self-identity might be outweighed by the income effect when it comes to energy-related high-impact behaviors. Thus, following the procedure of Hayes and Matthes (2009), we tested whether environmental self-identity moderates the effect of income on different behaviors by recalculating the regression analyses reported above. Income, environmental self-identity, and the interaction of income and self-identity were included as predictors (note that income and environmental self-identity were centered for this procedure; for details on the statistics as well as graphical representations, see online Appendix C.) The results showed the same main effects of income and environmental self-identity found in the previous regressions (with two exceptions: the effect of environmental self-identity did not reach a significant level in predicting living space, and income now significantly predicted the purchase of organic food). Visual inspection of high-impact behaviors (see Figures in online Appendix C) revealed, as expected, smoother increases between low and high incomes for people high in environmental self-identity. However, compared with those low in self-identity, none of the interaction terms reached a significant level in the statistical tests. Thus, our assumption of a moderating effect of environmental self-identity could not be confirmed with our data. 


\section{Discussion}

In this study, we investigated how individuals' environmental stance relates to their intent-driven pro-environmental behavior, on the one hand, and their actual environmental impact, on the other. Based on Stern's (2000) distinction between intent-oriented and impactoriented research perspectives on environmentally significant behavior, we sought to shed more light on the psychological and socioeconomic determinants of different behaviors varying in their degree in terms of environmental impact, as well as underlying psychological intention.

\section{Diverging Determinants of Intent-oriented versus Impact-oriented Behaviors}

Consistent with previous research (Bruderer Enzler \& Diekmann, 2015; Gatersleben et al., 2002; Kennedy et al., 2015; Whitmarsh, 2009), we found that participants' proenvironmental stance (i.e., "environmental self-identity" in this case) was the main predictor of their intent-oriented pro-environmental behavior. Unexpectedly, however, and in contrast to previous studies showing motivational variables to play a supportive - albeit marginal role (Bruderer Enzler \& Diekmann, 2015; Gatersleben et al., 2002; Kennedy et al., 2014, 2015; Keuschnigg \& Schubert, 2013; Whitmarsh, 2009), in our study environmental selfidentity was linked to environmental impact in an ambiguous, even controversial, manner: rather than using less energy, people high in environmental self-identity in our sample used slightly more energy and had a slightly bigger carbon footprint than those indicating less environmental awareness.

There are several possible explanations for these unexpected findings, which contrast with earlier studies. First, direct comparison with previous studies must be done with caution due to national and regional differences between sample populations. Differences with other studies exist in terms of infrastructural context, climatological specificities, and the $\mathrm{CO}_{2}$ intensity of the national energy mix. Two previous studies from Germany that might enable direct comparison were both focused on urban populations (Hunecke et al., 2007; 
Keuschnigg \& Schubert, 2013), whereas our German sample population was broad-based and more representative, including urban and rural areas. Our results point to a substantial mismatch between environmental self-identity and environmental impact with respect to daily transportation, or annual distances travelled. Notably, travel distances and travel modes strongly depend on geographical location: there tend to be more environmentally friendly travel options (e.g., public transport) in urban areas than in suburban or rural areas (Scheiner, 2010). Thus, future studies might look more closely at differences between geographical locations (e.g., rural vs. urban).

Second, direct comparison of our results with those of other studies is further complicated by differing operationalization of impact-oriented measures. For example, some studies report impact measures at the household level (e.g., Gatersleben et al., 2002; Kennedy et al., 2015), whereas we focused on per capita impacts. However, as shown in a study by Holden (2004), collinearity exists between household size and ecological awareness. Further, differences may arise based on the consumption domains chosen to measure overall environmental impact (e.g., whether air travel is included) or based on whether, and to what extent, indirect energy use is also accounted for. Finally, differences may result based on use of different assessment units, whether ecological footprint (e.g., in Csutora, 2012), energy use (e.g., in Abrahamse \& Steg, 2009; Gatersleben et al., 2002; Poortinga et al., 2004), or carbon footprint (e.g., in Bruderer Enzler \& Diekmann, 2015; Kennedy et al., 2014, 2015; Keuschnigg \& Schubert, 2013; Notter et al., 2013; Tabi, 2013). Indeed, use of more standardized assessment procedures would enhance the comparability of future studies. Moreover, future research might address the potential bias that could result from our procedure of mixing calculations of direct energy use (housing and transportation) and indirect energy use (food); this could be done by testing different combinations of calculation approaches, so as to enable estimation of the impact of different methodological choices. 
The third, and perhaps most interesting, possible explanation for our unexpected result could relate to the incoherent relationship structure between income (the dominant determinant of overall impact), environmental self-identity, and environmental impact. Our correlation analyses (see online Appendix B) revealed that both environmental impact and environmental self-identity increase steadily with rising income. The seemingly counterintuitive relationship between environmental self-identity and environmental impact found in the present study may result because individuals' genuinely felt pro-environmental stance is overridden by the overall effect of various consumption options that open up with higher socioeconomic status. In this way, any influence of pro-environmental motivation is counterbalanced by the "income effect". Evidence for this is suggested by the results of our moderator tests that revealed insignificant interaction effects. This suggests that the observed positive relationships between income and high-impact energy consumption behaviors holds for participants indicating high as well as low levels of environmental self-identity. Future studies should look more closely at these interdependences.

\section{Diverging Determinants of Different Behavior Indicators of Energy Use}

High-impact behaviors in the housing and transportation domains displayed an ambiguous relationship with environmental self-identity; in these domains, the behavior of participants reporting high levels of environmental self-identity tended to be more harmful, or at least no better, than the behavior of those reporting low levels of environmental selfidentify, an insight that was also supported by tests for potential moderating effects. Indeed, income and number of household members appeared to be the dominant determinants of high-impact behaviors in these domains. Notably, however, positive relationships were found between environmental self-identity and certain low-impact behaviors in the housing domain, in particular ownership of energy-efficient household appliances and purchasing of organic foods. Previous studies on environmental self-identity confirm its explanatory power vis-àvis low-impact behaviors, such as recycling, waste reduction, purchasing choice, showering 
duration, or the practice of fuel-efficient driving (Gatersleben et al., 2014; Nigbur et al., 2010; van der Werff et al., 2013a, 2013b; Whitmarsh \& O'Neill, 2010). Also consistent with our results, in earlier studies, no or only marginal associations were found between environmental self-identity and high-impact behaviors such as investing in energy-conserving home improvements, reducing car use, or flying less (Gatersleben et al., 2014; Nigbur et al., 2010; Whitmarsh \& O'Neill, 2010). Based on identity theory, several explanations are possible for this phenomenon. It may be that high-impact behavior decisions (travel mode choices, decisions about place of residence) are typically made in "environmental identity"incongruent contexts, i.e., contexts in which "being green" is not salient for people. Identitybased motivations may only translate into action in context conditions that activate a certain identity concept (Oyserman, 2009). Indeed, following the assumption of a multidimensional identity concept (Brekhus, 2008), it may be that typical decision contexts of high-impact behavior not only fail to activate people's "green" identity, but also trigger other personal or social identities that are incongruent with environmental protection, such as that of demonstrating belonging to a high-status in-group. We might conclude that certain decisions and behaviors appear more congruent with an environmental self-identity, while others (unfortunately the high-impact ones) fail to exert a strong enough ("green") identity-building function. Further research should more closely examine the symbolic functions of highimpact behaviors in relation to "being green" versus "being wealthy" (status). Further, we might also conclude that "being green" is not always easy. For example, it requires knowing the actual effectiveness of different behaviors (e.g., de Boer, Witt, \& Aiking, 2016), accepting financial and time-related costs, inconveniences, and giving up habits one holds dear. Self-identities include not only identity-congruent actions, but also identity-congruent mindsets used to make sense of the world; having an environmental self-identity may help individuals interpret the difficulties they face in a motivating way, but it may also have demotivating effects (Oyserman, 2009, 2014). 
Our results revealed one key, high-impact behavior that was an exception to this pattern: meat consumption. Indeed, lower meat consumption was predicted by higher levels of environmental self-identity, independent of income. This result is consistent with other recent studies (de Boer, Schösler, \& Boersema, 2013; van der Werff et al., 2013b; Whitmarsh \& O'Neill, 2010). Generally speaking, it appears that reducing meat consumption for environmental reasons is slowly gaining ground (Siegrist, Visschers, \& Hartmann, 2015).

Overall, our results support the conclusion that having a pro-environmental stance does not automatically lead to an environmentally friendly lifestyle. The findings suggest that environmentally aware people intend to behave in a pro-environmental manner, but they mainly focus on behaviors that have relatively small benefits. In other words, they have good intentions but only achieve minimal results in terms of overall environmental impact.

Our results may be explained with the assumption that environmental awareness may only result in environmentally significant behavior if the latter is congruent with the type of lifestyle afforded by one's income level. In this way, higher-income environmentally concerned people tend to buy energy-efficient appliances and environmentally sound products. However, for many of the same people, when environmentally significant behavior means curtailing consumption - e.g., refraining from car use or air travel, or living in smaller homes - their pro-environmental motivation fails to be decisive. Similar results were found in a recent French study (Cayla, Maizi, \& Marchand, 2011). These authors found a positive correlation between income and the intensity of energy use (e.g., weekly number of washing machine uses), whereas no correlation was found between income and energy-management practices (e.g., using a washing temperature of $30^{\circ} \mathrm{C}$ or $40{ }^{\circ} \mathrm{C}$, turning off lights, setting to standby mode, or reducing temperature of the home). In this way, the higher-income groups in this study tended to display practices similar to our intent-oriented behaviors, but used energy services much more intensively than lower-income groups (thus not exhibiting any curtailment in high-impact behaviors). 
Other studies point to competition between environmental concerns and consumptionoriented lifestyles within populations: Gatersleben et al. (2010) found that significant numbers of people exhibit both high environmental concerns and high materialistic values. Pro-environmental beliefs and materialistic beliefs may not contradict each other on a psychological level. However, in practice - on the level of impacts - they frequently do.

\section{Implications and Conclusions}

The present study was based on data derived from a larger survey representing one of the most extensive efforts to quantify per capita consumption of resources in Germany to date, in particular with respect to energy use and related greenhouse gas emissions. The assessment was based on a detailed item battery covering different consumption domains (e.g., even including pet ownership) in combination with interviewer observations. Nevertheless, our study has several limitations that should be considered when interpreting its results.

The first such limitation has to do with the comparability of impact measures (already discussed above) due to differences in assessment and calculation procedures used in different studies. Future research could benefit strongly from establishment and use of a standardized, validated assessment instrument. Notably, initial attempts in this direction have been made, for example, by Armel, Yan, Todd, and Robinson (2011).

A second study limitation involves our choice of psychological variables and operationalization. Behavior-specific motivational variables might display stronger links with high-impact behaviors (e.g., as found in Hunecke et al., 2007 for daily transportation) than we found for environmental self-identity. However, in the present study, we primarily sought to test how and whether people's general pro-environmental stance shapes their lifestyle and its environmental impacts, and we refrained from assessing psychological variables on a behavior-specific level. It was, however, a challenge to measure a motivational variable and a 
self-reported behavior variable at the same aggregation level as overall energy use and carbon footprint without being redundant in terms of questions asked for the assessment of environmental impacts. The item operationalization we used is only suitable to a limited extent. The high correlation between environmental self-identity and pro-environmental behavior found (cp. online Appendix B) likely reveals a lack of distinction between the items used. Future research might opt for a more intermediate level between specific behaviors (as commonly used in studies on pro-environmental behavior) and the overall aggregation level used in this study. This might enable the formulation of more distinct items.

Despite these limitations, we believe the findings of the present study give rise to several crucial insights and relevant questions for future research and policy. They call into question whether current studies, but also policy interventions, target the most relevant behaviors. Regarding studies, we strongly agree with other researchers who recommend focusing on high-impact behaviors (e.g., Bilharz \& Schmitt 2011; Gatersleben et al., 2002; Steg \& Vlek, 2009; Stern, 2000, 2011). Moreover, we believe that a broader approach focusing on behavior patterns or lifestyles, rather than specific behaviors - would add significant value to current methods of environmental psychological research.

\section{Acknowledgments}

We cordially thank our colleagues H.-Peter Neitzke, Elisabeth Lauper, and Anu Lannen, as well as Michael Bilharz from the German Environment Agency for their helpful comments on an earlier version of this article.

\section{Declaration of Conflicting Interests}

The author(s) declared no potential conflicts of interest with respect to the research, authorship, and/or publication of this article. 


\section{Funding}

The author(s) disclosed receipt of the following financial support for the research, authorship, and/or publication of this article: This research was supported by the the German Environment Agency (UBA), Dessau-Rosslau, Germany, UFOPLAN 3713 17311.

\section{Note}

1. Exchange rate of EUR ( $€$ ) to USD (\$) 1.38 on April 1, 2014.

\section{References}

Abrahamse, W., \& Steg, L. (2009). How do socio-demographic and psychological factors relate to households' direct and indirect energy use and savings? Journal of Economic Psychology, 30(5), 711-720. doi:10.1016/j.joep.2009.05.006

Armel, K. C., Yan, K., Todd, A., \& Robinson, T. N. (2011). The Stanford Climate Change Behavior Survey (SCCBS): Assessing greenhouse gas emissions-related behaviors in individuals and populations. Climatic Change, 109(3), 671-694. doi:10.1007/s10584-011$0031-y$

Bilharz, M., \& Schmitt, K. (2011). Going Big with Big Matters.The Key Point Approach to Sustainable Consumption. GAIA, 20(4), 232-235.

Brekhus, W. H. (2008). Trends in the qualitative study of social identities. Sociology Compass, 2, 1059-1078. doi: 10.1111/j.1751-9020.2008.00107.x

Bruderer Enzler, H., \& Diekmann, A. (2015). Environmental impact and pro-environmental behavior: Correlations to income and environmental concern. ETH Zurich Sociology Working Papers (Vol. 9). Zurich, Switzerland: ETH Zurich. 
Cayla, J.-M., Maizi, N., \& Marchand, C. (2011). The role of income in energy consumption behaviour: Evidence from French households data. Energy Policy, 39(12), 7874-7883. doi:10.1016/j.enpol.2011.09.036

Clayton, S., \& Myers, G. (2015). Conservation psychology: Understanding and promoting human care for nature. Chichester: Wiley-Blackwell.

Cook, A. J., Kerr, G. N., \& Moore, K. (2002). Attitudes and intentions towards purchasing GM food. Journal of Economic Psychology, 23(5), 557-572. doi:10.1016/S01674870(02)00117-4

Csutora, M. (2012). One more awareness gap? The behaviour-impact gap problem. Journal for Consumer Policy, 35(1), 145-163. doi:10.1007/s10603-012-9187-8

Čuček, L., Klemeš, J. J., \& Kravanja, Z.. (2012). A review of rootprint analysis tools for monitoring impacts on sustainability. Journal of Cleaner Production, 34, 9-20. doi:10.1016/j.jclepro.2012.02.036

de Boer, J., Schösler, H., \& Boersema, J. J. (2013). Climate change and meat eating: An inconvenient couple? Journal of Environmental Psychology, 33, 1-8. doi:10.1016/j.jenvp.2012.09.001

de Boer, J., de Witt, A., \& Aiking, H. (2016). Help the climate, change your diet: A crosssectional study on how to involve consumers in a transition to a low-carbon society. Appetite, 98, 19-27. doi:10.1016/j.appet.2015.12.001

European Environment Agengy (EEA). (2013). Environmental pressures from European consumption and production. A study in integrated environmental and economic analysis. EEA Technical Report (Vol. 2/2013). Kopenhagen: European Environment Agency. Retrieved from http://www.eea.europa.eu/publications/environmental-pressures-fromeuropean-consumption

Federal Statistical Office (2014). Wirtschaftsrechnungen. Laufende Wirtschaftsrechnungen Einnahmen und Ausgaben privater Haushalte [Economical accounts. Running economical 
accounts: Revenues and spendings of private households]. Wiesbaden: Federal Statistical Office. Retrieved from https://www.destatis.de/DE/Publikationen/Thematisch/EinkommenKonsumLebensbeding ungen/EinkommenVerbrauch/EinnahmenAusgabenprivaterHaushalte2150100147004.pdf? _blob=publicationFile

Federal Statistical Office (2015a). Bildungsstand der Bevölkerung [Population education level]. Wiesbaden: Federal Statistical Office. Retrieved from https://www.destatis.de/DE/Publikationen/Thematisch/BildungForschungKultur/Bildungss tand/BildungsstandBevoelkerung5210002157004.pdf?_blob=publicationFile

Federal Statistical Office (2015b). Umweltnutzung und Wirtschaft: Tabellen zu den Umweltökonomischen Gesamtrechnungen. Teil 2: Vorbericht Energie [Resource use and economy: Tables on ecological-economic national accounting. Part 2: Preliminary Report Energy]. Wiesbaden: Federal Statistical Office. Retrieved from https://www.destatis.de/DE/Publikationen/Thematisch/UmweltoekonomischeGesamtrechn ungen/Querschnitt/UmweltnutzungundWirtschaftTabelle5850007157006Teil_2.pdf?_blo $b=$ publicationFile

Federal Statistical Office (n.d.). Energieverbrauch: Energieverbrauch der privaten Haushalte für Wohnen (temperaturbereinigt) [Energy consumption: Energy consumption of private households for housing (adjusted for temperature)]. Retrieved from https://http://www.destatis.de/DE/ZahlenFakten/GesamtwirtschaftUmwelt/Umwelt/Umwe ltoekonomischeGesamtrechnungen/MaterialEnergiefluesse/Tabellen/EnergieverbrauchHa ushalte.html.

Fielding, K. S., McDonald, R., \& Louis, W. R. (2008). Theory of planned behaviour, identity and intentions to engage in environmental activism. Journal of Environmental Psychology, 28(4), 318-326. doi:10.1016/j.jenvp.2008.03.003 
Galli, A., Wiedmann, T., Ercin, E., Knoblauch, D., Ewing, B., \& Giljum, S. (2012). Integrating ecological, carbon and water footprint into a "footprint family" of indicators: Definition and role in tracking human pressure on the planet. Ecological Indicators, 16, 100-112. doi:10.1016/j.ecolind.2011.06.017

Gatersleben, B., Murtagh, N., \& Abrahamse, W. (2014). Values, identity and proenvironmental behaviour. Contemporary Social Science, 9(4), 374-392. doi:10.1080/21582041.2012.682086

Gatersleben, B., Steg, L., \& Vlek, C. (2002). Measurement and determinants of environmentally significant consumer behavior. Environment and Behavior, 34(3), 335362. doi:10.1177/0013916502034003004

Gatersleben, B., White, E., Abrahamse, W., Jackson, T., \& Uzzell, D. (2010). Values and sustainable lifestyles. Architectural Science Review, 53, 37-50. doi:10.3763/asre.2009.0101

German Environment Agengy (UBA) (2014). Vergleich der Emissionen einzelner Verkehrsträger im Personenverkehr - Bezugsjahr: 2011. [Comparison of emissions of different personal transport modes - base year 2011]. Retrieved from http://www.umweltbundesamt.de/themen/verkehr-laerm/emissionsdaten; last access 16.06.2015: since then only updated data availabe.

German Federal Statistical Office (StBA) (2011). Durchschnittliche Wohnfläche pro Person nach Haushaltstyp [Average per capita home size for different household types], Germany: Statistisches Bundesamt. Retrieved from https://www.destatis.de/DE/Methoden/Zensus_Tabellen/Wohnsituation_HH_Zensus11_ Wohnflaeche.html

Giesen, D., Meertens, V., Vis-Visschers, R., \& Beukenhorst, D. (2012). Questionnaire Development. The Hague: Statistics Netherlands. Retrieved from 
https://www.cbs.n1/nr/rdonlyres/99b7482f-e09e-4d86-90a1666dc42745bd/0/2012questionairedevelopmentart.pdf

Girod, B., \& de Haan, P. (2010). More or better? A model for changes in household greenhouse gas emissions due to higher income. Journal of Industrial Ecology, 14(1), 3147. doi:10.1111/j.1530-9290.2009.00202.x

Hayes, A. F., \& Matthes, J. (2009). Computational procedures for probing interactions in OLS and logistic regression: SPSS and SAS implementations. Behavior research methods, 41(3), 924-936. Doi:10.3758/BRM.41.3.924

Hinds, J., \& Sparks, P. (2008). Engaging with the natural environment: The role of affective connection and identity. Journal of Environmental Psychology, 28(2), 109-120. doi:10.1016/j.jenvp.2007.11.001

Holden, E. (2004). Towards sustainable consumption: Do green households have smaller ecological footprints? International Journal of Sustainable Development, 7(1), 44-58. doi:10.1504/IJSD.2004.004983

Hunecke, M., Hauenstein, S., Böhler, S., \& Grischkat, S. (2010). Attitude-based target groups to reduce the ecological impact of daily mobility behavior. Environment and Behavior, 42(1), 3-43. doi:10.1177/0013916508319587

Hunecke, M., Haustein, S., Grischkat, S., \& Böhler, S. (2007). Psychological, sociodemographic, and infrastructural factors as determinants of ecological impact caused by mobility behavior. Journal of Environmental Psychology, 27(4), 277-292. doi:10.1016/j.jenvp.2007.08.001

International Institute for Sustainability Analysis and Strategy (IINAS) (2012). Der nichterneuerbare Primärenergieverbrauch des nationalen Strommix in Deutschland im Jahr 2011 [The share of non-renewable primary energy consumption on the national electricity mix in Germany in the year 2011]. Bericht für die Fachgemeinschaft für effiziente Energieanwendungen e.V. (HEA). Darmstadt, Germany: Internationales Institut für 
Nachhaltigkeitsanalysen und -strategien. Retrieved from http://www.iinas.org/tl_files/iinas/downloads/GEMIS/2012_KEV-Strom-2011_HEA.pdf Intergovernmental Panel on Climate Change (IPCC) (2014). Climate change 2014: Synthesis report. Contribution of working groups I, II and III to the fifth assessment report of the Intergovernmental Panel on Climate Change. Geneva, Switzerland: Intergovernmental Panel on Climate Change. Retrieved from http://www.ipcc.ch/pdf/assessmentreport/ar5/syr/SYR_AR5_FINAL_full_wcover.pdf

Jungbluth, N., Itten, R., \& Stucki, M. (2012). Umweltbelastungen des privaten Konsums und Reduktionspotentiale [Environmental impact of private consumption and its reduction potentials]. Bern, Switzerland: Bundesamt für Umwelt.

Jones, C. M. \& Kammen, D. M. (2011). Quantifying carbon footprint reduction opportunities for U.S. households and communities. Environmental Science \& Technology, 45, 40884095. doi:10.1021/es102221

Kastner, I., \& Matthies, E. (2014). Motivation and impact. Implications of a twofold perspective on sustainable consumption for intervention programs and evaluation designs. GAIA, 23, 175-185.

Kennedy, E. H., Krahn, H., \& Krogman, N. T. (2014). Egregious emitters: Disproportionality in household carbon footprints. Environment and Behavior, 46(5), 535-555. doi:10.1177/0013916512474986

Kennedy, E. H., Krahn, H., \& Krogman, N. T. (2015). Are we counting what counts? A closer examination of environmental concern, pro-environmental behaviour, and carbon footprint. Local Environment, 20(2), 220-236. doi:10.1080/13549839.2013.837039.

Keuschnigg, M, \& Schubert, J. (2013). Münchner Umwelt-Survey: Privater Umweltverbrauch in den Bereichen Wohnen und Mobilität [Munich environmental survey: Private consumption in the housing and mobility domain]. Arbeitspapier des 
Instituts für Soziologie der Ludwig-Maximilians-Universität Münschen (Vol. Nr. 6).

Münschen, Germany: Institut für Soziologie.

Kleinhückelkotten S., \& Neitzke H.-P. (2016): Berechnung individueller Pro-KopfVerbräuche natürlicher Ressourcen nach Konsumbereichen. Anlagenband zum Bericht Repräsentative Erhebung von Pro-Kopf-Verbräuchen natürlicher Ressourcen in Deutschland (nach Bevölkerungsgruppen). [Assessment of domainspecific, individual percaptia consumption of natural resources. Technical report of the representative survey of per capita consumptions of natural resources in Germany (with respect to population segments) ]. Report 39/2016. Dessau-Rosslau: Umweltbundesamt. Retrieved from https://www.umweltbundesamt.de/sites/default/files/medien/378/publikationen/texte_39_2 016_anlagen_repraesentative_erhebung_von_pro-kopfverbraeuchen_natuerlicher_ressourcen.pdf

Kleinhückelkotten S., Neitzke H.-P., \& Moser, S. (2016): Repräsentative Erhebung von ProKopf-Verbräuchen natürlicher Ressourcen in Deutschland (nach Bevölkerungsgruppen). [Representative survey of per capita consumptions of natural resources in Germany (with respect to population segments)]. Report 39/2016. Dessau-Rosslau: Umweltbundesamt. Retrieved from https://www.umweltbundesamt.de/sites/default/files/medien/378/publikationen/texte_39_2 016_repraesentative_erhebung_von_pro-kopf-verbraeuchen_natuerlicher_ressourcen.pdf Kutzner, F., Hertle, H., \& Lambrecht, U. (2014). Die Umweltwirkungsperspektive: Bilanzierung der persönlichen Treibhausgasemissionen in einer standardisierten Erhebung. [The environmental impact perspective: Accounting of personal greenhouse gase emissions in a standardized survey]. In M. Hunecke \& A. Toprak (Eds.), Empowerment von Migrant_innen zum Klimaschutz [Empowerment of migrants for climate protection]. (pp. 23-46). Munich, Germany: Oekom-Verlag. 
Max Rubner-Institute (MRI), (2008). Nationale Verzehrsstudie II. Ergebnisbericht, Teil 2 [National Consumption Survey II. Result Report part 2]. Karlsruhe, Germany: Max Rubner-Institut. Retrieved from http://www.bmel.de/SharedDocs/Downloads/Ernaehrung/NVS_ErgebnisberichtTeil2.pdf;j sessionid $=$ CA4C3FE27AC9D9435C6F42D5019F0204.2_cid376?_blob=publicationFile

Nigbur, D., Lyons, E., \& Uzzell, D.. (2010). Attitudes, norms, identity and environmental behaviour: Using an expanded theory of planned behaviour to predict participation in a kerbside recycling programme. British Journal of Social Psychology, 49(2), 259-284. doi:10.1348/014466609X449395

Notter, D. A., Meyer, R., \& Althaus, H.-J. (2013). The western lifestyle and its long way to sustainability. Environmental Science \& Technology, 47(9), 4014-4021 doi:10.1021/es3037548

Oyserman, D. (2009). Identity-based motivation: Implications for action-readiness, procedural-readiness, and consumer behavior. Journal of Consumer Psychology, 19, 250260. doi: 10.1016/j.jeps.2009.05.008

Oyserman, D. (2014). Identity-based motivation: Core processes and intervention examples. In S. A. Karabenick \& T. C. Urdan (Eds.), Motivational interventions (pp. 213-242). Emerald Group Publishing Limited.

Poortinga, W., Steg, L., \& Vlek, C. (2004). Values, environmental concern, and environmental behavior: A study into household energy use. Environment and Behavior, 36(1), 70-93. doi:10.1177/0013916503251466

Scheiner, J. (2010). Interrelations between travel mode choice and trip distance: Trends in Germany 1976-2002. Journal of Transport Geography, 18(1), 75-84. doi:10.1016/j.jtrangeo.2009.01.001 
Seebauer, S., Fleiss, J., \& Schweighart, M. (2016). A household is not a person: Consistency of pro-environmental behavior in adult couples and the accuracy of proxyreports. Environment and Behavior, online first. doi:10.1177/0013916516663796.

Siegrist, M., Visschers, V. H. M., \& Hartmann, C.. (2015). Factors influencing changes in sustainability perception of various food behaviors: Results of a longitudinal study. Food Quality and Preference, 46, 33-39. doi:10.1016/j.foodqual.2015.07.006

Sparks, P., \& Shepherd, R.. (1992). Self-Identity and the theory of planned behavior: Assesing the role of identification with "green consumerism". Social Psychology Quarterly, 55(4), 388-399. doi:10.2307/2786955

Steg, L., \& Vlek, C. (2009). Encouraging pro-environmental behaviour: An integrative review and research agenda. Journal of Environmental Psychology, 29(3), 309-317. doi:10.1016/j.jenvp.2008.10.004

Steg, L., Bolderdijk, J. W., Keizer, K., \& Perlaviciute, G. (2014). An integrated framework for encouraging pro-environmental behaviour: The role of values, situational factors and goals. Journal of Environmental Psychology, 38(0), 104-115. doi:10.1016/j.jenvp.2014.01.002

Stern, P. C. (2000). Toward a coherent theory of environmentally significant behavior. The Journal of Social Issues, 56(3), 407-424.

Stern, P. C. (2011). Contributions of psychology to limiting climate change. The American Psychologist, 66(4), 303-314. doi:10.1037/a0023235

Tabi, A. (2013). Does pro-environmental behaviour affect carbon emissions? Energy Policy, 63, 972-981. doi:10.1016/j.enpol.2013.08.049

Thøgersen, J., \& Grønhøj, A. (2010). Electricity saving in households-A social cognitive approach. Energy Policy, 38(12), 7732-7743. doi:10.1016/j.enpol.2010.08.025 
Thøgersen, J., \& Ölander, F. (2006). To what degree are environmentally beneficial choices reflective of a general conservation stance? Environment and Behavior, 38(4), 550-569. doi:10.1177/0013916505283832

Tukker, A., \& Jansen, B. (2006). Environmental impacts of products: A detailed review of studies. Journal of Industrial Ecology, 10(3), 159-182. doi:10.1162/jiec.2006.10.3.159

UN General Assembly (2015). Transforming our world: The 2030 agenda for sustainable development. New York, NY: UN General Assembly. Retrieved from https://sustainabledevelopment.un.org/content/documents/21252030\%20Agenda $\% 20$ for $\%$ 20Sustainable\%20Development\%20web.pdf

United Nations Environment Program (UNEP), (2010). Assessing the environmental impacts of consumption and production: Priority products and materials. A Report of the Working Group on the Environmental Impacts of Products and Materials to the International Panel for Sustainable Resource Management. United Nations Environment Program. Retrieved from http://www.unep.fr/shared/publications/pdf/DTIx1262xPAPriorityProductsAndMaterials_Report.pdf van der Werff, E., Steg, L., \& Keizer, K. (2013a). It is a moral issue: The relationship between environmental self-identity, obligation-based intrinsic motivation and proenvironmental behaviour. Global Environmental Change, 23(5), 1258-1265. doi:10.1016/j.gloenvcha.2013.07.018

van der Werff, E., Steg, L., \& Keizer, K. (2013b). The value of environmental self-identity: The relationship between biospheric values, environmental self-identity and environmental preferences, intentions and behaviour. Journal of Environmental Psychology, 34, 55-63. doi:10.1016/j.jenvp.2012.12.006

Weidema, B. P., Thrane, M., Christensen, P., Schmidt, J., \& Løkke, S. (2008). Carbon footprint. Journal of Industrial Ecology, 12(1), 3-6. doi:10.1111/j.15309290.2008.00005.x 
Whitmarsh, L. (2009). Behavioural responses to climate change: Asymmetry of intentions and impacts. Journal of Environmental Psychology, 29(1), 13-23. doi:10.1016/j.jenvp.2008.05.003

Whitmarsh, L., \& O'Neill, S. (2010). Green identity, green living? The role of proenvironmental self-identity in determining consistency across diverse pro-environmental behaviours. Journal of Environmental Psychology, 30(3), 305-314. doi:10.1016/j.jenvp.2010.01.003

Wiedmann, T., \& Minx, J. (2008). A definition of 'carbon footprint'. In C. C. Pertsova (Ed.), Ecological Economics Research Trends (pp. 1-11). Happauge: Nova Science Publishers.

\section{Author Biographies}

Stephanie Moser is a senior research scientist in the Centre for Development and Environment at the University of Bern, Switzerland. Her research focuses on individual and societal processes regarding the diffusion of sustainable behaviors.

Silke Kleinhückelkotten is senior research scientist and co-director of the ECOLOG-Institut für sozial-ökologische Forschung und Bildung, Hannover. Her research focuses on sustainable lifestyles, environmental concerns, social marketing, and education for sustainable development. 
Table 1

Socioeconomic sample characteristics

\begin{tabular}{|c|c|c|c|}
\hline Characteristics & $M$ & $S D$ & $\%$ \\
\hline Age in years & 49.8 & 17.6 & \\
\hline Net monthly per capita income in $€$ (income) & $1,186.7$ & 624.3 & \\
\hline Number of household members & 2.5 & 1.2 & \\
\hline \multicolumn{4}{|l|}{ Gender } \\
\hline male & & & 49.1 \\
\hline female & & & 50.9 \\
\hline \multicolumn{4}{|l|}{$\begin{array}{l}\text { Highest education level completed } \\
\text { (education) }\end{array}$} \\
\hline secondary school & & & 39.5 \\
\hline intermediate school & & & 32.7 \\
\hline higher education entrance qualification & & & 20.7 \\
\hline higher education & & & 5.6 \\
\hline missing & & & 1.5 \\
\hline \multicolumn{4}{|l|}{ Home ownership } \\
\hline rental & & & 72.2 \\
\hline owns home & & & 27.8 \\
\hline \multicolumn{4}{|l|}{ Residential area } \\
\hline urban & & & 59.2 \\
\hline rural & & & 40.8 \\
\hline
\end{tabular}


Table 2

Descriptive statistics of pro-environmental behavior, overall energy use, carbon footprint, and different indicators of energy use

\begin{tabular}{|c|c|c|c|c|c|c|c|c|c|}
\hline & $\begin{array}{c}\text { Research } \\
\text { perspective }\end{array}$ & $N$ & $M$ & $S D$ & Median & Min & $\operatorname{Max}$ & $\begin{array}{c}\text { Skew- } \\
\text { ness }\end{array}$ & Kurtosis \\
\hline \multicolumn{10}{|l|}{ Overall measures } \\
\hline Pro-environmental behavior ${ }^{1}$ & intent & 1,007 & 2.94 & .90 & 3 & 1 & 5 & .08 & -.55 \\
\hline Overall energy use (kWh/a) & impact & 1,012 & $13,677.22$ & $7,130.92$ & $12,057.20$ & $2,673.58$ & $7,4284.06$ & 1.90 & 7.57 \\
\hline Carbon footprint $\left(\mathrm{kgCO}_{2} \mathrm{e} / \mathrm{a}\right)$ & impact & 1,012 & $4,547.20$ & $2 ’ 189.53$ & $4,046.54$ & $1,068.24$ & $1,8097.01$ & 1.56 & 3.77 \\
\hline \multicolumn{10}{|l|}{ Housing } \\
\hline Living space $\left(\mathrm{m}^{2}\right)$ per person & impact & 1,002 & 40.19 & 19.99 & 35 & 5 & 305 & 3.72 & 34.09 \\
\hline Household appliances (kWh/a) & impact & 1,012 & 525.60 & 289.81 & 444.55 & 109.35 & 2954.40 & 2.11 & 7.99 \\
\hline Energy-efficient appliances ${ }^{2}$ & intent & 960 & .72 & .84 & .50 & 0 & 5 & 1.46 & 2.39 \\
\hline \multicolumn{10}{|l|}{ Food } \\
\hline Meat consumption ${ }^{3}$ & impact & 1,011 & 3.10 & .93 & 3 & 1 & 6 & .74 & 1.38 \\
\hline Organic foods ${ }^{4}$ & intent & 1,009 & 2.98 & .79 & 3 & 1 & 4 & -.59 & -.09 \\
\hline \multicolumn{10}{|l|}{ Transportation } \\
\hline Car trips $(\mathrm{km} / \mathrm{a})^{5}$ & impact & 962 & 2.93 & 1.98 & 3 & 0 & 8 & -.11 & -.80 \\
\hline Vacation trips $(\mathrm{km})^{6}$ & impact & 512 & 4.99 & 1.31 & 5 & 1 & 8 & .24 & .10 \\
\hline
\end{tabular}

Notes. 'Answer categories from $1=$ "I totally agree" to $5=$ "I totally disagree". "Number of energy-efficient household appliances A ${ }^{+}$to A ${ }^{+++}$.

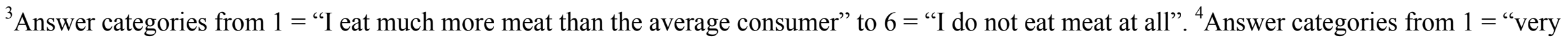

important" to $4=$ "not at all important". "Answer categories from $1=$ "less than 1,000 km" to $8=$ "more than 30,000 per year"; people who never use personal cars were coded as $0 .{ }^{6}$ Answer categories from $1=$ ' 1 to $50 \mathrm{~km}$ " to $8=$ "more than $5,000 \mathrm{~km}$ "; people who did not go for vacation in the last year were coded as missing. 
Table 3

Regression analyses for pro-environmental behavior, overall energy use, and carbon footprint

\begin{tabular}{|c|c|c|c|c|c|c|c|c|c|}
\hline & \multicolumn{3}{|c|}{ Pro-environmental behavior } & \multicolumn{3}{|c|}{ Overall energy use (kWh/a) } & \multicolumn{3}{|c|}{ Carbon footprint $\left(\mathrm{kgCO}_{2} \underline{\mathrm{e} / \mathrm{a})}\right.$} \\
\hline & $B$ & S.E. & $\beta$ & $B$ & S.E. & $\beta$ & $B$ & S.E. & $\beta$ \\
\hline Constant & 1.10 & .16 & & 4.17 & .05 & & 3.68 & .05 & \\
\hline Age & .00 & .00 & .00 & .00 & .00 & $-.12 * *$ & .00 & .00 & $-.13 * * *$ \\
\hline Gender $($ male $=0)$ & -.05 & .04 & -.03 & -.06 & .01 & $-.13 * * *$ & -.06 & .01 & $-.16 * * *$ \\
\hline Education & -.04 & .03 & -.04 & .00 & .01 & -.02 & .00 & .01 & .00 \\
\hline Income & .00 & .00 & -.01 & .00 & .00 & $.25 * * *$ & .00 & .00 & $.27 * * *$ \\
\hline N. of household members & -.01 & .03 & -.01 & -.02 & .01 & $-.10^{*}$ & -.02 & .01 & $-.09 *$ \\
\hline Owns home $($ rental $=0)$ & -.07 & .05 & -.03 & .10 & .02 & $.22 * * *$ & .08 & .01 & $.19 * * *$ \\
\hline Urban vs. rural region & .07 & .04 & .04 & .00 & .01 & .01 & .00 & .01 & -.01 \\
\hline Environmental self-identity & .66 & .02 & $.70 * * *$ & -.02 & .01 & $-.09 * *$ & -.02 & .01 & $-.08 * *$ \\
\hline$R^{2} / R^{2} a d j$ & & $.52 / .51$ & & & $.19 / .19$ & & & $.20 / .19$ & \\
\hline$F$ & & $123.03 * * *$ & & & $27.46 * * *$ & & & $28.97 * * *$ & \\
\hline$N$ & & 934 & & & 935 & & & 935 & \\
\hline
\end{tabular}

Notes. All variables were entered simultaneously into the equation. ${ }^{*} p<.05,{ }^{* *} p<.01,{ }^{* * *} p<.001$. Due to their skewed distribution, overall energy use and carbon footprint were log-transformed. 
Table 4

Regression analyses for different indicators of energy use in the housing domain

\begin{tabular}{|c|c|c|c|c|c|c|c|c|c|}
\hline & \multicolumn{3}{|c|}{ Living space $\left(\mathrm{m}^{2}\right)$} & \multicolumn{3}{|c|}{ Household appliances (kWh/a) } & \multicolumn{3}{|c|}{ Energy-efficient appliances } \\
\hline & $B$ & S.E. & $\beta$ & $B$ & S.E. & $\beta$ & $B$ & S.E. & $\beta$ \\
\hline Constant & 1.63 & .03 & & 3.00 & .05 & & 1.50 & .20 & \\
\hline Age & .00 & .00 & $.10 * * *$ & -.00 & .00 & $-.09 *$ & -.01 & .00 & $-.18 * * *$ \\
\hline Gender $($ male $=0)$ & .01 & .01 & .03 & .00 & .01 & .00 & .14 & .05 & $.08 * *$ \\
\hline Education & .01 & .00 & .03 & -.02 & .01 & $-.09 * *$ & -.02 & .03 & -.02 \\
\hline Income & .00 & .00 & $.21 * * *$ & .00 & .00 & $.09 *$ & .00 & .00 & $.21 * * *$ \\
\hline N. of household members & -.09 & .00 & $-.58 * * *$ & -.08 & .01 & $-.42 * * *$ & -.16 & .03 & $-.22 * * *$ \\
\hline Owns home $($ rental $=0)$ & .15 & .01 & $.37 * * *$ & .01 & .02 & .02 & .30 & .06 & $.16 * * *$ \\
\hline Urban vs. rural region & .01 & .01 & .02 & -.00 & .01 & -.01 & -.06 & .05 & -.03 \\
\hline Environmental self-identity & -.01 & .00 & $-.04 *$ & -.03 & .01 & $-.13 * * *$ & -.13 & .03 & $-.15 * * *$ \\
\hline$R^{2} / R^{2} a d j$ & \multicolumn{3}{|c|}{$.65 / .64$} & \multicolumn{3}{|c|}{$.22 / .21$} & \multicolumn{3}{|c|}{$.19 / .18$} \\
\hline$F$ & \multicolumn{3}{|c|}{$209.10 * * *$} & \multicolumn{3}{|c|}{$32.79 * * *$} & \multicolumn{3}{|c|}{$25.06 * * *$} \\
\hline$N$ & \multicolumn{3}{|c|}{927} & \multicolumn{3}{|c|}{935} & \multicolumn{3}{|c|}{892} \\
\hline
\end{tabular}

Note. All variables were entered simultaneously into the equation. ${ }^{*} p<.05,{ }^{* *} p<.01,{ }^{* * *} p<.001$. Due to their skewed distribution, home size, and household appliances were log-transformed. 
Table 5:

Regression analyses for different indicators of energy use in the food and transportation domain

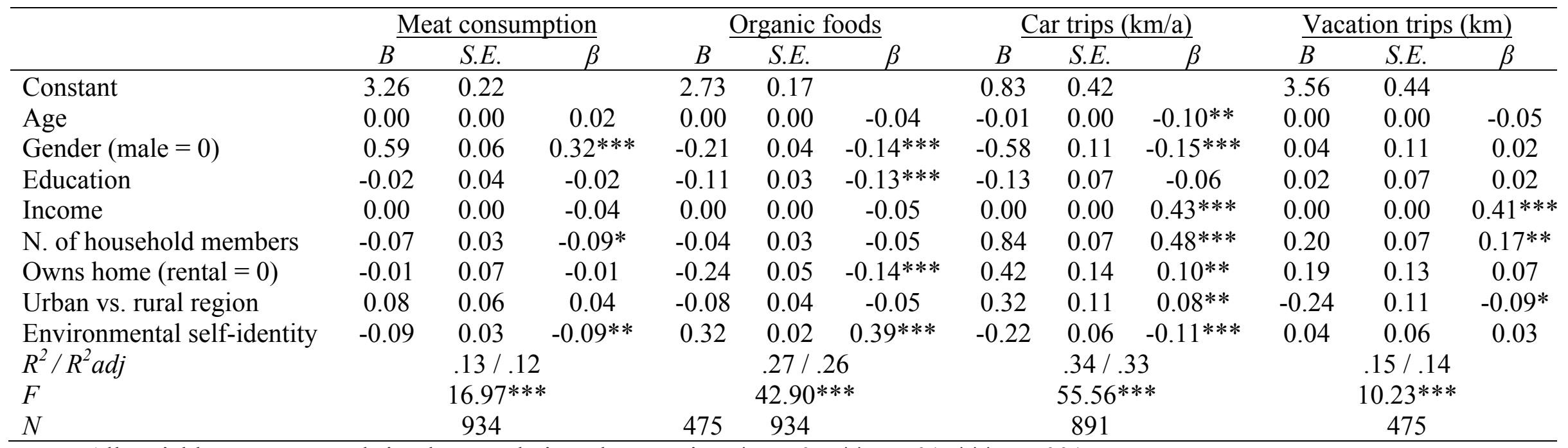

Note. All variables were entered simultaneously into the equation. ${ }^{*} p<.05,{ }^{* *} p<.01,{ }^{* * *} p<.001$. 


\section{Appendix A}

Illustration of different elements included in our assessment of overall per capita energy use

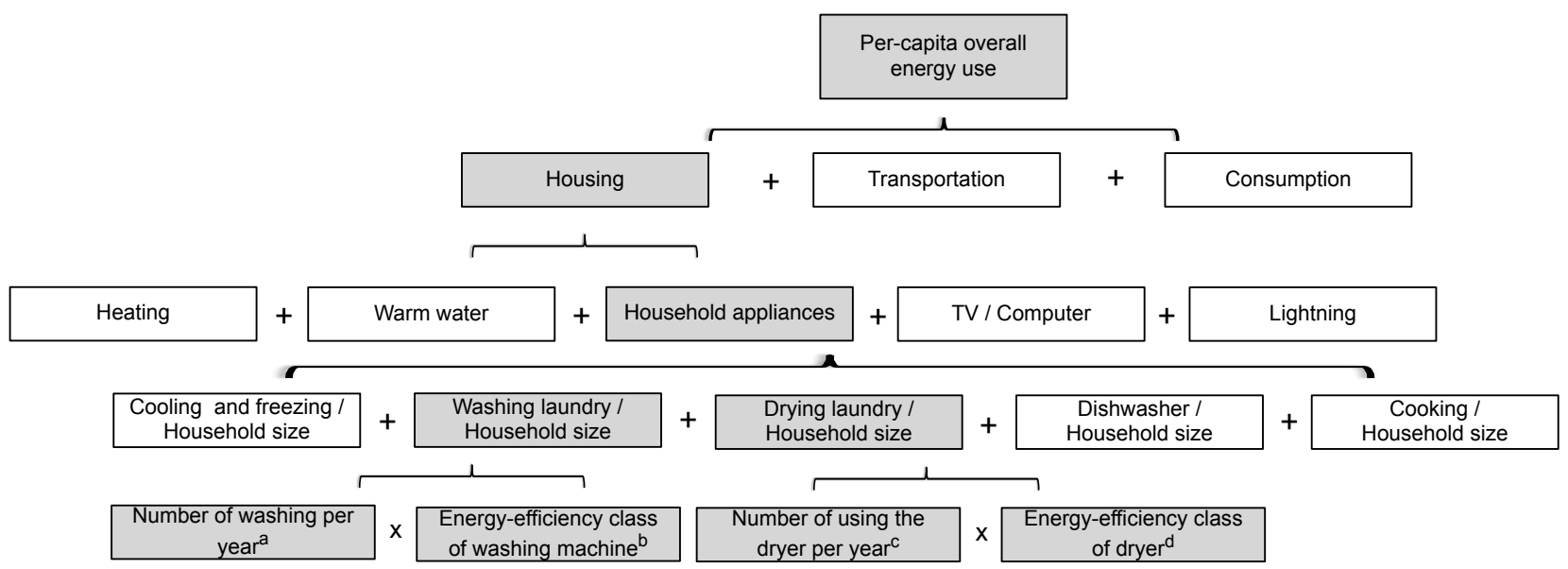

Figure A1. Detailing the example of laundry (as part of the energy use of household appliances).

Notes. Elements shown in grey-highlighted rectangles are described in greater detail at each descending level, for details see Kleinhückelkotten and Neitzke (2016).

a Item in the questionnaire read as follows: "How many loads of laundry do you wash in your washing machine on average?"; answer categories ranged from 1 = "fewer than 1 per week" to $5=$ "more than 10 per week". For answer category 1, we assumed 26 loads of laundry per year; for answer category 5, we assumed 650 loads of laundry per year.

${ }^{b}$ Item in the questionnaire read as follows: "What kind of washer do you use?". Answer categories ranged from 1 = "a washer of the energy-efficiency class A+ to A+++" to 4 = "an old washer without an energy class rating". Our assumptions on the energy consumption per laundry load for different washing-machine energy-efficiency classes were based on Blepp, Gross, \& Quark, 2012; German Environment Agency (UBA) (2012); VZRP, 2012a.

${ }^{c}$ Items in the questionnaire read as follows: "How many loads of laundry do you dry in your dryer on average?"; answer categories ranged from 1 = "fewer than 1 per week" to $5=$ "more than 10 per week".

dem in the questionnaire read as follows: "What kind of dryer do you use?". Answer categories ranged from 1 = "a dyer of the energy-efficiency class A+ to A+++" to 4 = "an old dryer without an energy class rating". Our assumptions on the energy consumption per laundry load for different dryer energy-efficiency classes were based on VZRP, 2012b. For clothesline (hang) drying of laundry, an energy consumption value of 0 was entered. 


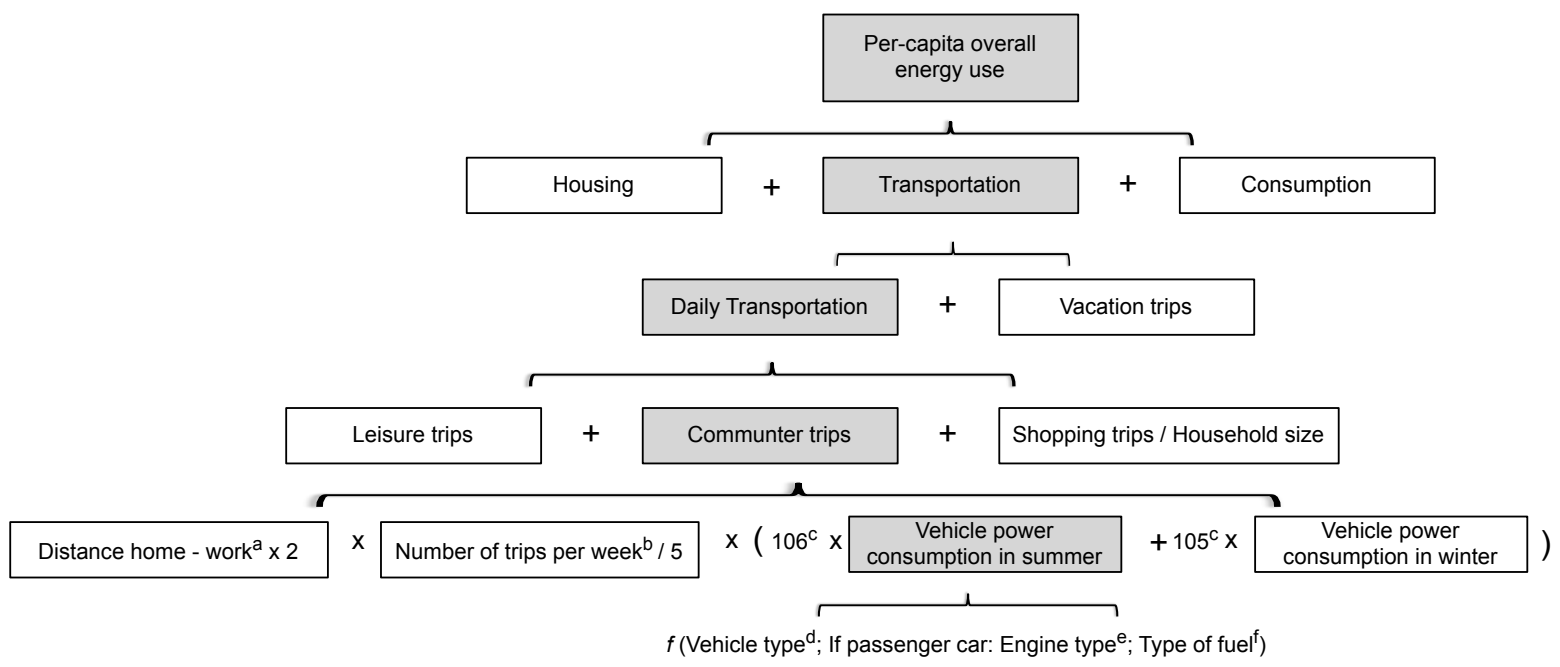

Figure A2. Detailing the example of commuter trips (as part of the energy use of daily transportation).

Notes. Elements shown in grey-highlighted rectangles are described in greater detail at each descending level, for details see Kleinhückelkotten and Neitzke (2016).

a Item in the questionnaire read as follows: "How far is it from your home to your workplace or school (only one way)?"; answer categories ranged from $1=$ "less than $5 \mathrm{~km}$ " to $6=$ "more than $100 \mathrm{~km}$ ". We controlled for trips from secondary residences; none of the participants commuted to work from a secondary residence.

${ }^{\mathrm{b}}$ Item read as follows: "How often per week do you commute from your home to your work place or school?"

${ }^{\mathrm{c}}$ Average number of working days for the year 2013, in summer, and in winter (based on Federal Statistical Office 2014b)

d Item read as follows: "Which of the following transportation modes do you usually use for the trip from your home to your working place or school? Please indicate the transportation mode you use for the summer season, and for the winter season." Participants could choose among the following transport modes: passenger car, city bus, tramway or suburban train, bicycle, e-bike, walking, long-distance train, remote bus, motorcycle, moped, airplane, taxi, or detailing another option. The consumption data used for different transportation modes stems from DEKRA 2014; German Environment Agengy (UBA) 2014; 2012b, Verkehrsklub Deutschland (VCD) 2012; Walnum 2011.

${ }^{\mathrm{e}}$ Item read as follows: "Is your passenger car powered by a gas engine, an electric engine, or a hybrid engine?" 
f Item read as follows: "What kind of fuel powers the passenger car you use?" Participants could choose among petrol, diesel, petroleum gas, liquefied gas, or biofuel.

\section{References}

Blepp, M., Gross, R., \& Quack, D. (2012). PROSA Kurzstudie Waschsalons: Entwicklung der Vergabekriterien für ein klimaschutzbezogenes Umweltzeichen [PROSA study launderette: Development of criteria for climate saving certifications]. Berlin, Germany: Öko-Institut DEKRA. (2014). Informationen zum Thema CO 2: Ergebnisse aus den Verbrauchsmessungen im Standard-Fahrzyklus (ECE) [Informations about CO 2: Results from consumption measuring for standard driving cycles]. Stuttgart, Germany: DEKRA. Retrieved from http://www.dekra-online.de/co2/ co2_rechner.html

Federal Statistical Office. (2014). Wirtschaftsrechnungen. Laufende Wirtschaftsrechnungen Einnahmen und Ausgaben privater Haushalte [Economical accounts. Running economical accounts: Revenues and spendings of private households]. Wiesbaden, Germany: Author. Retrieved from https://www.destatis.de/DE/Publikationen/Thematisch/EinkommenKonsumLebensbedingu ngen/EinkommenVerbrauch/EinnahmenAusgabenprivaterHaushalte2150100147004.pdf?_ _blob=publicationFile

German Environment Agengy. (2012a). Vergleich des Energieverbrauchs bei

Waschmaschinen [Comparison of the energy consumption of washing machines]. DessauRosslau, Germany: Umweltbundesamt. Retrieved from http://www.umweltbundesamt.de/sites/default/files/medien/pdfs/waschmaschinen_energiek osten.pdf

German Environment Agengy. (2012b). Daten zum Verkehr [Statistics on traffic]. DessauRosslau, Germany: Umweltbundesamt. Retrieved from https://www.umweltbundesamt.de/sites/default/files/medien/publikation/long/4364.pdf German Environment Agengy. (2014). Vergleich der Emissionen einzelner Verkehrsträger im Personenverkehr-Bezugsjahr: 2011 [Comparison of emissions of different personal transport modes-Base year 2011]. Retrieved from http://www.umweltbundesamt.de/themen/verkehr-laerm/emissionsdaten Kleinhückelkotten, S., \& Neitzke, H.-P. (2016). Berechnung individueller Pro-KopfVerbräuche natürlicher Ressourcen nach Konsumbereichen. Anlagenband zum Bericht Repräsentative Erhebung von Pro-Kopf-Verbräuchen natürlicher Ressourcen in 
Deutschland (nach Bevölkerungsgruppen) [Assessment of domainspecific, individual percaptia consumption of natural resources. Technical report of the representative survey of per capita consumptions of natural resources in Germany (with respect to population segments)] (Report No. 39). Dessau-Rosslau, Germany: Umweltbundesamt. Retrieved from https://www.umweltbundesamt.de/ sites/default/files/medien/378/publikationen/texte_39_2016_anlagen_repraesentative_erheb ung_von_pro-kopf-verbraeuchen_natuerlicher_ressourcen.pdf

Verkehrsklub Deutschland. (2012, February). Auch mit Motor klimafreundlich. Die Ökobilanz von Elektrofahrrädern kann sich sehen lassen — und wird mit regenerativ erzeugtem Strom noch besser [Climate friendly even with motor: The eco-balance of electric bicycle is worth a look-And even better with renewable energy]. VCD Magazin Fairkehr.

Verbraucherzentrale Rheinland-Pfalz e.V., \& Öko-Institut e.V. (2012a). Energieverbrauch von Waschmaschinen [Energy consumption of washing machines]. Mainz, Germany: Verbraucherzentrale Rheinland-Pfalz.

Verbraucherzentrale Rheinland-Pfalz e.V., \& Öko-Institut e.V. (2012b). Energieverbrauch von Wäschetrocknern [Energy consumption of tumblers]. Mainz, Germany: Verbraucherzentrale Rheinland-Pfalz.

Walnum, H. J. (2011). Energy use and CO2 emissions from cruise ships - A discussion of methodological issues (Vestlandsforsking-note nr. 2/2011). Sogndal: Western Norway Research Institute. 
Appendix B:

\section{Correlation Analysis}

As shown in Table B1 we found unexpected, albeit weak, negative correlations between pro-environmental behavior and our two environmental-impact measures. Note that the answer scale for pro-environmental behavior was coded such that low values mean high estimates of pro-environmental behavior. In other words, participants who viewed themselves as making an effort to behave in an environmentally friendly manner actually tended to consume more energy on average $(r=-.12, p<.001)$ and to emit more greenhouse gases $(r=-.12, p<.001)$ than those who did not.

Going further, our analysis of correlations among pro-environmental behavior and specific behavior indicators revealed associations in the expected direction for the following: ownership of energy-efficient household appliances, consumption of meat, and importance of organic foods. Conversely, no or unexpected correlations were found between proenvironmental behavior, on the one hand, and living space, energy consumption of household appliances and our two transportation indicators, on the other. Participants with higher levels of self-reported pro-environmental behavior lived in larger homes $(r=-.11, p=.001)$, used more energy in the kitchen and for laundry $(r=-.07, p=.022)$, drove longer distances in passenger vehicles $(r=-.11, p=.001)$, and did not refrain from long-distance vacations $(r=-$ $.05, p=.315)$. Notably, these four indicators - living space, household appliances, passenger car use, and vacation travel - were also the biggest contributors to overall energy use, so this observed mismatch with self-perceived pro-environmental behavior is highly relevant. 
Table B1:

Correlations among outcome variables and predictors

\begin{tabular}{|c|c|c|c|c|c|c|c|c|c|c|c|c|c|c|c|c|c|c|}
\hline & & 1 & 2 & 3 & 4 & 5 & 6 & 7 & 8 & 9 & 10 & 11 & 12 & 13 & 14 & 15 & 16 & 17 \\
\hline 1 & Pro-environmental behavior $^{1}$ & & & & & & & & & & & & & & & & & \\
\hline 2 & Overall energy use $(\mathrm{kWh} / \mathrm{a})$ & $-.12 * *$ & & & & & & & & & & & & & & & & \\
\hline 3 & Carbon footprint $\left(\mathrm{kgCO}_{2} \mathrm{e} / \mathrm{a}\right)$ & $-.12 * *$ & $.97 * *$ & & & & & & & & & & & & & & & \\
\hline 4 & Living space $\left(\mathrm{m}^{2}\right)$ per person & $-.11 * *$ & $.40^{* *}$ & $.38 * *$ & & & & & & & & & & & & & & \\
\hline 5 & Household appliances $(\mathrm{KWh} / \mathrm{a})$ & $-.07 *$ & $.29 * *$ & $.31 * *$ & $.37 * *$ & & & & & & & & & & & & & \\
\hline 6 & Energy-efficient appliances ${ }^{2}$ & $-.22 * *$ & $.26^{* *}$ & $.24 * *$ & $.33 * *$ & .06 & & & & & & & & & & & & \\
\hline 7 & Meat consumption $^{3}$ & $-.12 * *$ & $-.21 * *$ & $-.23 * *$ & .04 & -.05 & .06 & & & & & & & & & & & \\
\hline 8 & Organic foods ${ }^{4}$ & $.44^{* *}$ & -.04 & -.03 & $-.10 * *$ & $.09^{* *}$ & $-.22 * *$ & $-.23 * *$ & & & & & & & & & & \\
\hline 9 & Car trips $(\mathrm{km} / \mathrm{a})^{5}$ & $-.11^{* *}$ & $.48^{* *}$ & $.48^{* *}$ & -.03 & -.01 & $.18^{* *}$ & $-.21 * *$ & $-.12 * *$ & & & & & & & & & \\
\hline 10 & Vacation trips $(\mathrm{km})^{6}$ & -.05 & $.33^{* *}$ & $.37 * *$ & $.11^{*}$ & .03 & $.13^{* *}$ & -.06 & $-.10^{*}$ & $.25 * *$ & & & & & & & & \\
\hline 11 & Age & .02 & -.03 & -.05 & $.36^{* *}$ & $.11^{* *}$ & -.05 & .05 & .02 & $-.22 * *$ & -.04 & & & & & & & \\
\hline 12 & Gender $($ male $=0)$ & $-.10 * *$ & $-.16 * *$ & $-.20 * *$ & .00 & .01 & $.07 *$ & $.35 * *$ & $-.17 * *$ & $-.18 * *$ & .00 & .015 & & & & & & \\
\hline 13 & Education & $-.15 * *$ & $.14^{* *}$ & $.16^{* *}$ & $.07 *$ & $-.07 *$ & $.12 * *$ & -.03 & $-.22 * *$ & $.20 * *$ & $.20 * *$ & $-.322 * *$ & .00 & & & & & \\
\hline 14 & Income & $-.12 * *$ & $.34 * *$ & $.36 * *$ & $.58 * *$ & $.27 * *$ & $.33 * *$ & -.01 & $-.13 * *$ & $.20 * *$ & $.32 * *$ & $.093 * *$ & $-.06^{*}$ & $.31^{* *}$ & & & & \\
\hline 15 & N. of household members & -.02 & $-.12 * *$ & $-.12 * *$ & $-.63 * *$ & $-.42 * *$ & $-.22 * *$ & $-.07 *$ & -.06 & $.32 * *$ & -.03 & $-.409 * *$ & -.01 & $.14^{* *}$ & $-.48 * *$ & & & \\
\hline 16 & Owns home (rental $=0$ ) & $-.16^{* *}$ & $.26^{* *}$ & $.23 * *$ & $.32 * *$ & -.05 & $.15^{* *}$ & -.02 & $-.24 * *$ & $.25 * *$ & $.19^{* *}$ & $.088^{* *}$ & -.04 & $.19^{* *}$ & $.18^{* *}$ & $.19 * *$ & & \\
\hline 17 & Urban vs. rural region & $.07 *$ & .01 & .00 & -.03 & -.04 & -.04 & .02 & -.03 & $.09 * *$ & -.07 & $-.064 *$ & .01 & .04 & .00 & $.07 *$ & .02 & \\
\hline 18 & Environmental self-identity ${ }^{4}$ & $.71^{* *}$ & $-.15 * *$ & $-.13 * *$ & $-.11 * *$ & $-.13 * *$ & $-.20 * *$ & $-.11 * *$ & $.44 * *$ & $-.16 * *$ & -.02 & .041 & $-.11 * *$ & $-.13 * *$ & $-.14 * *$ & -.02 & $-.15 * *$ & .05 \\
\hline
\end{tabular}

Notes. $r=$ Pearson correlation coefficient, ${ }^{*} p<.05, * * p<.01 .{ }^{1}$ Answer categories from $1=$ "I totally agree" to $5=$ "I totally disagree". ${ }^{2}$ Number of energy-efficient household appliances in classes $\mathrm{A}^{+}$to $\mathrm{A}^{+++} \cdot{ }^{3}$ Answer categories from $1=$ "I eat much more meat than the average consumer" to $6=$ "I do not eat meat at all". "Answer categories from $1=$ "very important" to 4 = "not at all important". "Answer categories from $1=$ "less than $1,000 \mathrm{~km}$ " to $8=$ "more than $30,000 \mathrm{~km}$ per year", whereas people who never use personal cars were coded as $0 .{ }^{6}$ Answer categories from $1=$ " 1 to $50 \mathrm{~km}$ " to $8=$ "more than $5,000 \mathrm{~km}$ ", whereas people who did not go for vacation in the last year were coded as missing. 
Appendix C:

Statistics and Figures of the Moderation Analyses

Table C1: Linear models predicting pro-environmental behavior, overall energy use, and carbon footprint (moderation analysis)

\begin{tabular}{|c|c|c|c|c|c|c|c|c|c|c|c|c|}
\hline & \multicolumn{4}{|c|}{$\underline{\text { Pro-environmental behavior }}$} & \multicolumn{4}{|c|}{ Overall energy use (kWh/a) } & \multicolumn{4}{|c|}{ Carbon footprint $\left(\mathrm{kgCO}_{2}{ }^{\mathrm{e} / \mathrm{a})}\right.$} \\
\hline & $B$ & S.E. & $t$ & $p$ & $B$ & S.E. & $t$ & $p$ & $B$ & S.E. & $t$ & $p$ \\
\hline Constant & 2.92 & .02 & 140.21 & .000 & 4.09 & .01 & 629.63 & .000 & 3.61 & .01 & 608.57 & .000 \\
\hline Env. Self-identity (centered) & .68 & .02 & 29.65 & .000 & -.02 & .01 & -3.49 & .001 & -.02 & .01 & -3.08 & .002 \\
\hline Income (centered) & .00 & .00 & -1.03 & .306 & .00 & .00 & 9.06 & .000 & .00 & .00 & 9.76 & .000 \\
\hline Income x Env. Self-identity & -.00 & .00 & -1.49 & .138 & .00 & .00 & .90 & .364 & .00 & .00 & 1.27 & .205 \\
\hline$R^{2}$ & \multicolumn{4}{|c|}{.51} & \multicolumn{4}{|c|}{.13} & \multicolumn{4}{|c|}{.14} \\
\hline$N$ & \multicolumn{4}{|c|}{945} & \multicolumn{4}{|c|}{946} & \multicolumn{4}{|c|}{946} \\
\hline
\end{tabular}

Notes. Due to their skewed distribution, overall energy use and carbon footprint were log-transformed.

Table C2: Linear models predicting energy indicators in the housing domain (moderation analysis)

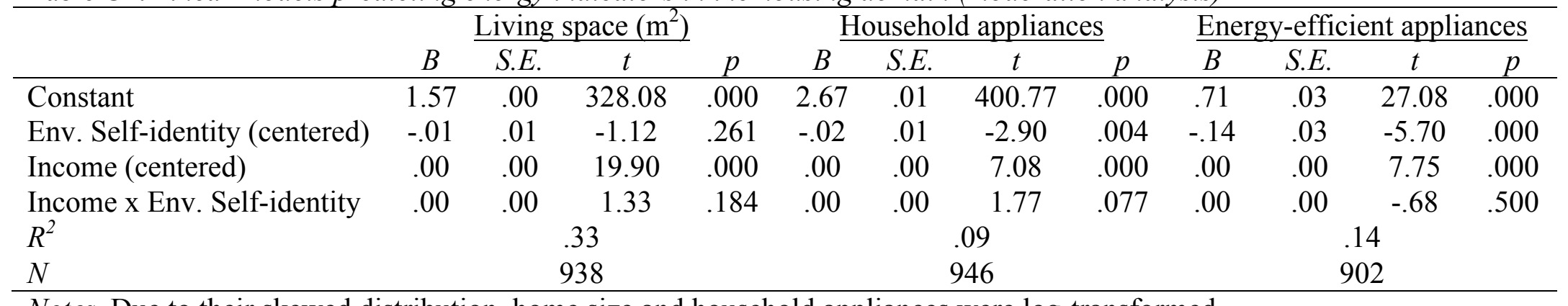

Notes. Due to their skewed distribution, home size and household appliances were log-transformed. 
Table C3: Linear models predicting energy indicators in the food domain (moderation analysis)

\begin{tabular}{|c|c|c|c|c|c|c|c|c|}
\hline & \multicolumn{4}{|c|}{ Meat consumption } & \multicolumn{4}{|c|}{ Organic foods } \\
\hline & $B$ & S.E. & $t$ & $p$ & $B$ & S.E. & $t$ & $p$ \\
\hline Constant & 3.11 & .03 & 103.03 & .000 & 3.00 & .02 & 130.77 & .000 \\
\hline Env. Self-identity (centered) & -.11 & .03 & -2.93 & .003 & .35 & .02 & 14.14 & .000 \\
\hline Income (centered) & .00 & .00 & -.43 & .670 & -.00 & .00 & -2.21 & .027 \\
\hline Income x Env. Self-identity & .00 & .00 & .56 & .579 & .00 & .00 & .79 & .427 \\
\hline$R^{2}$ & & & .01 & & & & 21 & \\
\hline$N$ & & & 45 & & & & 45 & \\
\hline
\end{tabular}

Table C4: Linear models predicting energy indicators in the transportation domain (moderation analysis)

\begin{tabular}{|c|c|c|c|c|c|c|c|c|}
\hline & \multicolumn{4}{|c|}{ Car trips $(\mathrm{km} / \mathrm{a})$} & \multicolumn{4}{|c|}{ Vacation trips $(\mathrm{km})$} \\
\hline & $B$ & S.E. & $t$ & $p$ & $B$ & S.E. & $t$ & $p$ \\
\hline Constant & 2.94 & .06 & 45.76 & .000 & 5.03 & .06 & 89.42 & .000 \\
\hline Env. Self-identity (centered) & -.31 & .07 & -4346 & .000 & -.01 & .06 & -.15 & .881 \\
\hline Income (centered) & .00 & .00 & 6.12 & .000 & .00 & .00 & 6.79 & .000 \\
\hline Income x Env. Self-identity & .00 & .00 & .44 & 662 & .00 & .00 & .59 & .556 \\
\hline$R^{2}$ & \multicolumn{4}{|c|}{.06} & \multicolumn{4}{|c|}{.10} \\
\hline$N$ & \multicolumn{4}{|c|}{901} & \multicolumn{4}{|c|}{480} \\
\hline
\end{tabular}




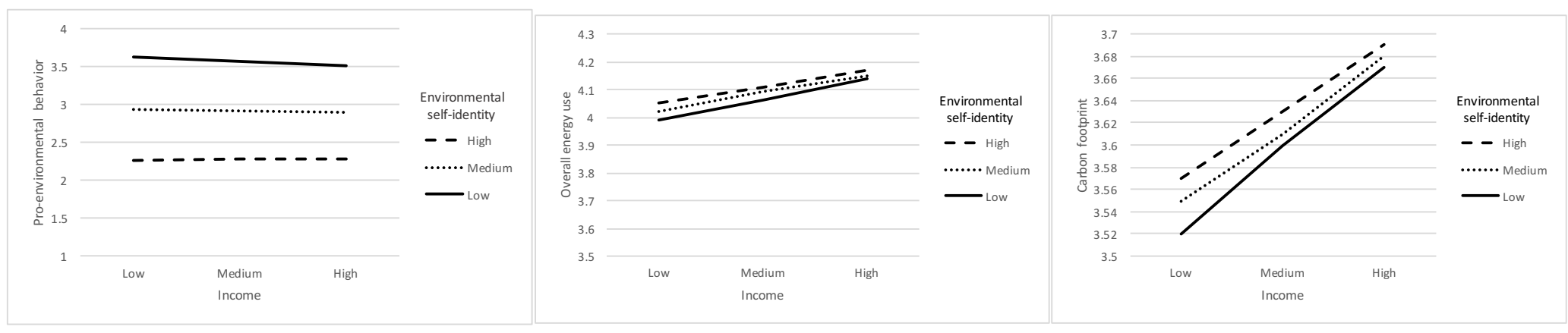

Figure $\mathrm{C} 1$. Visual depictions of the interactions between environmental self-identity and income for pro-environmental behavior (left), overall energy use (medium), and carbon footprint (right). Notes. For income: Medium = Mean income $(€ 1,186.7)$, Low / High $= \pm 1 S D(624.3)$. For

Environmental self-identity: Medium = Mean (2.94 on a scale from 1 to 5), Low / High $= \pm 1 S D(.94)$.
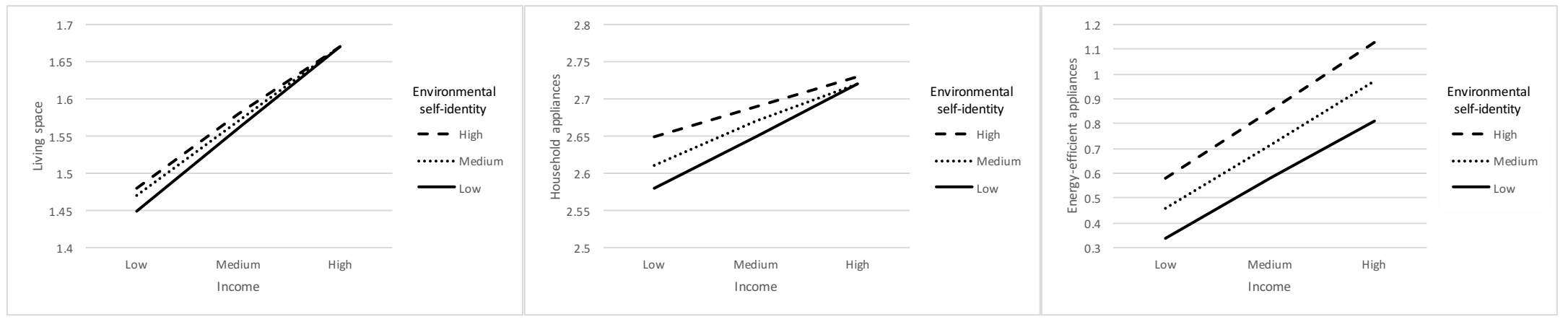

Figure C2. Visual depictions of the interactions between environmental self-identity and income for energy indicators in the housing domain. Notes.

For income: Medium = Mean income (1,186.7€), Low / High = $1 S D$ (624.3). For Environmental self-identity: Medium = Mean (2.94 on a scale from 1 to 5), Low / High $= \pm 1 S D(.94)$. 


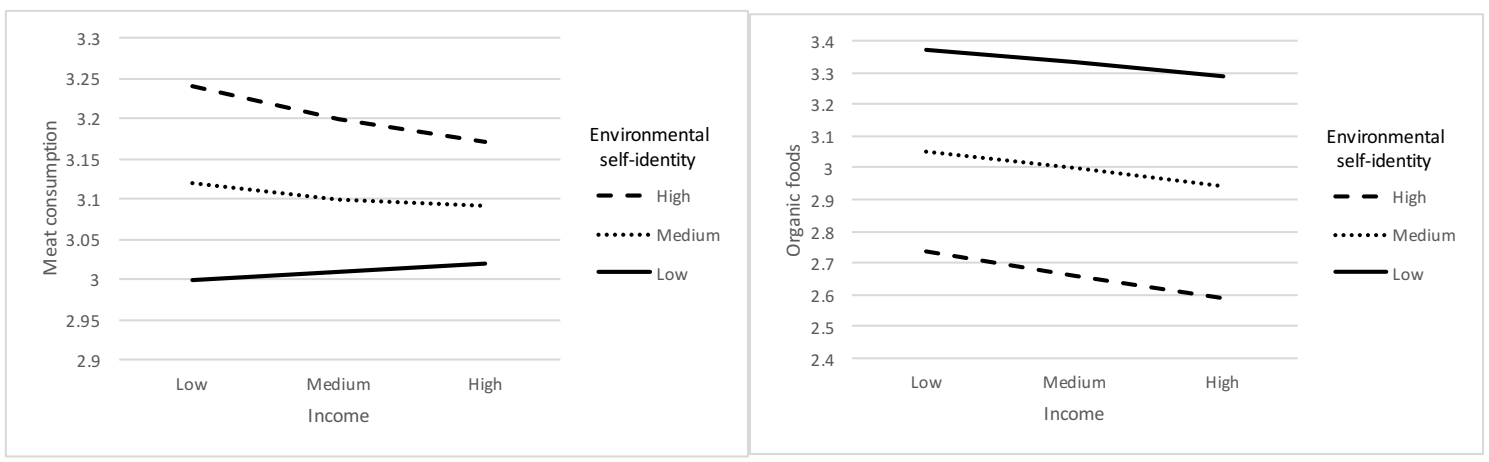

Figure C3. Visual depictions of the interactions between environmental self-identity and income for energy indicators in the food domain. Notes. For income: Medium $=$ Mean income $(€ 1,186.7)$, Low $/$ High $= \pm 1 S D$ (624.3). For Environmental self-identity: Medium = Mean (2.94 on a scale from 1 to 5), Low / High $= \pm 1 S D(.94)$.
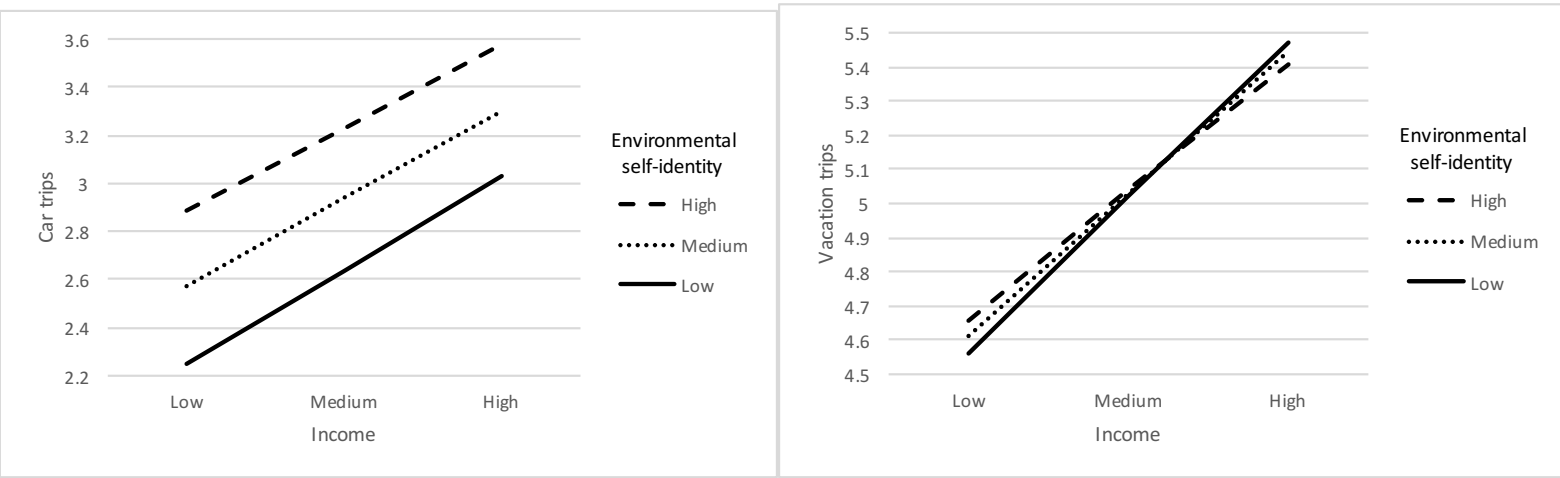

Figure C4. Visual depictions of the interactions between environmental self-identity and income for energy indicators in the transportation domain. Notes. For income: Medium = Mean income $(€ 1,186.7)$, Low / High $= \pm 1 S D$ (624.3). For Environmental self-identity: Medium $=$ Mean (2.94 on a scale from 1 to 5), Low / High $= \pm 1 S D(.94)$. 